\title{
Future change of global monsoon in the CMIP5
}

\author{
June-Yi Lee $\cdot$ Bin Wang
}

Received: 1 August 2012/ Accepted: 8 October 2012/Published online: 30 October 2012

(C) The Author(s) 2012. This article is published with open access at Springerlink.com

\begin{abstract}
This study investigates future changes of Global Monsoon (GM) under anthropogenic global warming using 20 coupled models that participated in the phase five of Coupled Model Intercomparison Project (CMIP5) by comparing two runs: the historical run for 1850-2005 and the Representative Concentration Pathway (RCP) 4.5 run for 2006-2100. A metrics for evaluation of models' performance on GM is designed to document performance for 1980-2005 and best four models are selected. The four best models' multi-model ensemble (B4MME) projects the following changes in the twenty-first century under the RCP4.5 scenario. (1) Monsoon domain will not change appreciably but land monsoon domain over Asia tends to expand westward by $10.6 \%$. (2) The annual mean and range of GM precipitation and the percentage of local summer rainfall will all amplify at a significant level over most of the global region, both over land and over ocean. (3) There will be a more prominent northern-southern hemispheric asymmetry and eastern-western hemispheric asymmetry. (4) Northern Hemisphere (NH) monsoon onset will be advanced and withdrawal will be delayed. (5) Changes in monsoon precipitation exhibits huge differences between the $\mathrm{NH}$ and the Southern hemisphere (SH). The NH monsoon precipitation will increase significantly due to increase in temperature difference between the $\mathrm{NH}$ and SH, significant enhancement of the Hadley circulation, and atmospheric moistening, against stabilization of troposphere. There is a slight decrease of the Walker circulation but not significant against the inter-model spread.
\end{abstract}

J.-Y. Lee $\cdot$ B. Wang $(\bowtie)$

Department of Meteorology and International Pacific Research

Center, University of Hawaii/IPRC, POST Bldg, Room 409E,

1680 East-West Road, Honolulu, HI 96822, USA

e-mail: wangbin@hawaii.edu
There are important differences between the CMIP 3 and CMIP5 results which are discussed in detail.

Keywords Global monsoon precipitation . Global warming · Future change - CMIP5 . Walker circulation $\cdot$ Hadley circulation

\section{Introduction}

The Intergovernmental Panel on Climate Change (IPCC) Fourth assessment report (AR4) stated that the current understanding of future climate change in the monsoon regions remains one of considerable uncertainty with respect to circulation and precipitation (IPCC AR4 Sections 3.7, 8.4.10 and 10.3.5.2). Although multi-model projections of precipitation change generally show a "rich-gets-richer" pattern, projections strongly depend on region. An increase in precipitation is projected in the Asian monsoon (along with an increase in interannual season-averaged precipitation variability) and the southern part of the west African monsoon with some decrease in the Sahel in northern summer, as well as an increase in the Australian monsoon in southern summer in a warmer climate. Differently from precipitation, Asian monsoon circulation was projected to decrease by $15 \%$ (Tanaka et al. 2005; Ueda et al. 2006). The monsoonal precipitation in Mexico and Central America is projected to decrease in association with increasing precipitation over the eastern equatorial Pacific through Walker Circulation and local Hadley Circulation changes. However, the uncertain role of aerosols complicates the nature of future projections of monsoon precipitation, particularly in the Asian monsoon.

Monsoon, in the generic sense, is a response of the coupled atmosphere-land-ocean system to the annual variation in solar forcing (Wang et al. 2011). Over the past 
decade, the Global Monsoon (GM) has been viewed as a global-scale, persistent atmospheric overturning that varies according to the time of year (Trenberth et al. 2000; Trenberth and Stepaniak 2004). Wang and Ding (2008) defined the GM as the dominant mode of the annual variation of the tropical precipitation and low-level winds, which characterize the seasonality of Earth's climate. Thus, the annual variation of all regional monsoons can be viewed as an integrated GM system. Changes in the regional monsoons cannot be fully understood unless we consider within a global perspective. Unfortunately, the change of the monsoons on global scale under increasing greenhouse gases forcing and aerosols has not been clearly documented. Recently, Hsu et al. (2012) showed that most models in the CMIP3 and CMIP5 project an increase of global monsoon area and precipitation under global warming mainly attributable to the increases of moisture convergence and surface evaporation. However, evaluation of models' historical simulations and estimation of uncertainty in the corresponding future projections are prerequisite to assessment of the future changes. These will be carefully examined in the present study.

Due to lack of observations over ocean, GM precipitation cannot be fully studied until recently. It has been recognized that GM precipitation over land decreased from 1950 to 1980, but leveled off after 1980 (Wang and Ding 2006). Satellite estimate of oceanic monsoon rainfall indicated an increasing trend over the recent three decades (Wang and Ding 2006) which has increased the total GM rainfall (Wang et al. 2012; Hsu et al. 2011). Wang et al. (2012) attributed the recent increasing trend to (a) increased land-ocean and inter-hemispheric thermal contrasts, and (b) natural multi-decadal variability that induced Eastern Pacific (EP) cooling-Western Pacific (WP) warming. The increasing land-ocean and inter-hemispheric thermal gradients are likely a consequence of the anthropogenic forcing (Wang et al. 2012) because the projected future temperature change shows a robust warm Northern Hemisphere (NH)-cold Southern Hemisphere ( $\mathrm{SH}$ ) and warm land-cold ocean warming pattern (Chou et al. 2007). In addition, the majority of the climate models in IPCC AR4 projected an EP warming or reduced SST gradient across the equatorial Pacific under increasing greenhouse gases forcing (Meehl et al. 2007b). However, it is difficult to quantify what GM precipitation changes should be expected in future under anthropogenic global warming because climate models tend to agree poorly on standard measures of such changes (Neelin et al. 2006).

This study investigates the future changes of GM projected by the 20 Coupled General Circulation Models (CGCMs) that participated in the phase five of the Coupled Model Intercomparison Project (CMIP5) by comparing two runs: the historical run under changing solar-volcanic forcing and anthropogenic influences from 1850 to 2005 and the Representative Concentration Pathway (RCP) 4.5 run assuming that radiative forcing will stabilize with an increases of about $4.5 \mathrm{Wm}^{-2}$ after 2100 (Taylor et al. 2012). We also analyze the third phases of the CMIP (CMIP3) twentieth century Climate in Coupled Model (20C3M) simulation from 1950 to 1999 and the Special Report on Emissions Scenarios (SRES) balance across all sources (A1B, 720 ppm stabilization experiment) from 2050 to 2099 (Meehl et al. 2007a) in comparison with the CMIP5 simulations. Detailed description of the model and data used is given in Sect. 2. Section 3 evaluates historical simulations of the 20 coupled models against the observation for the period of 1980-2005. Spatial distribution of the GM future change and transient response are discussed in Sects. 4 and 5, respectively. Section 6 summarizes the results.

\section{Model and data}

\subsection{Models and experiments}

Total 20 CGCMs participated in the CMIP5 are used in this study. Table 1 lists the model name, institution and horizontal resolution of atmospheric component. Two experiments are investigated. One is the historical run (i.e., the twentieth century run) from 1850 to 2005 and the other is the RCP 4.5 run from 2006 to 2100 . The historical run was imposed changing conditions consistent with observations which may include atmospheric composition (including $\mathrm{CO}_{2}$ ) due to both anthropogenic and volcanic influences, solar forcing, emissions or concentrations of short-lived species and natural and anthropogenic aerosols or their precursors, and land use. The RCP4.5 run assumes that radiative forcing will increase and then stabilize at about $4.5 \mathrm{Wm}^{-2}$ after 2100 and is chosen as a "central" scenario in CMIP5 (Taylor et al. 2012).

Seven models (CanESM2, GFDL-ESM2M, HadGEM2CC, HadGEM2-ES, MIROC-ESM, MPI-ESM, and NorESM1-M) in the CMIP5 are Earth System Models (ESM). They include bio-geochemical components that account for the important fluxes of carbon between the ocean, atmosphere, and terrestrial biosphere carbon reservoirs and may in some cases include interactive prognostic aerosol, chemistry, and dynamical vegetation components (Taylor et al. 2012). Thus, CMIP5 models may have larger response to natural forcing and aerosols than CMIP3 CGCMs (Yeh et al. 2012). Some of CMIP5 CGCMs perform simulations with a higher resolution or a more complete treatment of atmospheric chemistry than CMIP3 CGCMs. One can find detailed information on CMIP5 models and experiments at http://cmip-pcmdi.llnl.gov/ cmip5/experiment_design.html and some related papers (e.g., Taylor et al. 2012). 
Table 1 Description of CMIP5 models used in the study

\begin{tabular}{|c|c|c|c|}
\hline Institution & $\begin{array}{l}\text { Coupled } \\
\text { model }\end{array}$ & $\begin{array}{l}\text { AGCM resolution } \\
\text { Lon. } \times \text { Lat. }\end{array}$ & Ens no \\
\hline $\begin{array}{l}\text { Commonwealth Scientific and Industrial Research Organisation and } \\
\text { Bureau of Meteorology, Australia (CSIRO-BOM) }\end{array}$ & ACCESS1-0 & $1.875^{\circ} \times 1.25^{\circ}$ & 1 \\
\hline Beijing Climate Center, China Meteorological Administration (BCC) & BCC-CSM1.1 & $2.8125^{\circ} \times 2.8125^{\circ}$ & 1 \\
\hline Canadian Centre for Climate Modelling and Analysis (CCCma) & CanESM2 & $2.8125^{\circ} \times 2.8125^{\circ}$ & 5 \\
\hline National Center for Atmospheric Research (NCAR) & CCSM4 & $1.25^{\circ} \times 0.9375^{\circ}$ & 1 \\
\hline $\begin{array}{l}\text { Centre National de Recherches Meteorologiques/Centre Europeen de } \\
\text { Recherche et Formation Avancees en Calcul Scientifique (CNRM- } \\
\text { CERFACS) }\end{array}$ & CNRM-CM5 & $1.40625^{\circ} \times 1.40625^{\circ}$ & 1 \\
\hline $\begin{array}{l}\text { Commonwealth Scientific and Industrial Research Organisation and the } \\
\text { Queensland Climate Change Centre of Excellence (CSIRO-QCCCE) }\end{array}$ & CSIRO-Mk3-6-0 & $1.875^{\circ} \times 1.875^{\circ}$ & 3 \\
\hline $\begin{array}{l}\text { LASG, Institute of Atmospheric Physics, Chinease Academy of Sciences; } \\
\text { and CESS, Tsinghua University (LASG-CESS) }\end{array}$ & FGOALS-g2 & $2.8125^{\circ} \times 2.8125^{\circ}$ & 1 \\
\hline \multirow[t]{2}{*}{ Geophysical Fluid Dynamics Laboratory (NOAA GFDL) } & GFDL-CM3 & $2.5^{\circ} \times 2^{\circ}$ & 1 \\
\hline & GFDL-ESM2M & $2.5^{\circ} \times 2^{\circ}$ & 1 \\
\hline NASA Goddard Institute for Space Studies (NASA GISS) & GISS-E2-R & $2.5^{\circ} \times 2^{\circ}$ & 2 \\
\hline \multirow[t]{2}{*}{ Met Office Hadley Centre (MOHC) } & HadGEM2-CC & $1.875^{\circ} \times 1.24^{\circ}$ & 1 \\
\hline & HadGEM2-ES & $1.875^{\circ} \times 1.24^{\circ}$ & 1 \\
\hline Institute for Numerical Mathematics (INM) & INM-CM4 & $2^{\circ} \times 1.5^{\circ}$ & 1 \\
\hline \multirow[t]{2}{*}{ Institute Pierre-Simon Laplace (IPSL) } & IPSL-CM5A-LR & $3.75^{\circ} \times 1.875^{\circ}$ & 4 \\
\hline & IPSL-CM5A-MR & $2.5^{\circ} \times 1.258^{\circ}$ & \\
\hline \multirow{2}{*}{$\begin{array}{l}\text { Atmosphere and Ocean Research Institute (University of Tokyo), } \\
\text { National Institute for Environmental Studies, and Japan Agency } \\
\text { for Marine-Earth Science and Technology (MIROC) }\end{array}$} & MIROC5 & $1.40625^{\circ} \times 1.40625^{\circ}$ & 1 \\
\hline & MIROC-ESM & $2.8125^{\circ} \times 2.8125^{\circ}$ & 1 \\
\hline Max Planck Institute for Meteorology (MPI-M) & MPI-ESM-LR & $1.875^{\circ} \times 1.875^{\circ}$ & 3 \\
\hline Meteorological Research Institute (MRI) & MRI-CGCM3 & $1.125^{\circ} \times 2.25^{\circ}$ & 1 \\
\hline Norwegian Climate Centre (NCC) & NorESM1-M & $2.5^{\circ} \times 1.875^{\circ}$ & 1 \\
\hline
\end{tabular}

Models in red are selected for the four best models in terms of simulating global monsoon precipitation during historical run period of 1980-2005

In general, the CMIP5 CGCMs have a larger number of ensemble simulations for the historical run than for the RCP4.5 run. For more fair comparison, we use the same number of ensemble members for the two runs in individual models. Table 1 shows the number of ensemble members used for each model. To validate the CGCMs in their historical simulations with respect to observation, each model run was interpolated to a common $2.5^{\circ}$ lat $\times 2.5^{\circ}$ lon grid. The multi-model ensemble (MME) mean was constructed with equal weights. Model climatology was obtained for the 26 years of 1980-2005.

The CMIP3 multi-model simulations are also used in this study in comparison with the CMIP5 simulations. We analyze the 20C3M from 1950 to 1999 and the SRESA1B from 2050 to 2099 (Meehl et al. 2007a). One can find detail information on the CMIP3 models and experiments at http://www-pcmdi.llnl.gov/ipcc/standard_output.html\# Experiments and some related papers (e.g., Meehl et al. 2007a, b).

\subsection{Observation}

Monthly precipitation data used in this study were obtained from (1) the Climate Prediction Center (CPC) Merged Analysis of Precipitation (CMAP) dataset (Xie and Arkin 1997) from 1979 to 2010, (2) Global Precipitation Climatology Project (GPCP) data version 2.2 from 1979 to 2010 (Huffman et al. 2009) provided by the National Oceanic \& Atmospheric Administration (NOAA)/Earth System Research Laboratory (ESRL) Physical Sciences Division (PSD), and (3) the twentieth century merged statistical analyses of historical monthly precipitation anomalies REConstructed Globally (hereafter 20C RECG) from 1900 to 2008 (Smith et al. 2010). The twentieth century reanalysis (20CR) data (Compo et al. 2011) are used for monthly surface temperature, mean sea level pressure, horizontal wind, specific humidity, and air temperature from 1871 to 2010 . All observed data were interpolated to a common $2.5^{\circ}$ lat $\times 2.5^{\circ}$ lon grid. Same as the model data, observed climatology was obtained for the 26 years 
of 1980-2005. As a basic reference of precipitation, merged CMAP and GPCP precipitation with equal weight is used. It is noted that the difference between CMAP and GPCP is not significant in terms of climatology. The pattern correlation coefficient between CMAP and GPCP climatology is $0.95,0.94,0.95,0.96$, and 0.96 for annual mean, March-April-May (MAM), June-July-August (JJA), September-October-November (SON), and DecemberJanuary-February (DJF precipitation, respectively, over $60^{\circ} \mathrm{S}-60^{\circ} \mathrm{N}, 0^{\circ}-360^{\circ} \mathrm{E}$.

\section{Evaluation and selection of CMIP 5 models}

We assess the 20 CMIP5 CGCMs in simulating GM precipitation during the historical run period of 1980-2005 in terms of a simple metrics proposed by Wang and Ding (2008) that was designed to better understand the physical processes by which the coupled atmosphere-land-ocean system respond to the solar radiative forcing. The metrics includes (1) the annual mean precipitation, (2) the first and second annual cycle modes of annual variation of precipitation (i.e. the solstice mode and equinox asymmetric mode), (3) GM precipitation intensity and domain. The performance on GM precipitation domain reflects models' capability in simulation of the seasonal distribution of precipitation as well as the total amount of annual precipitation at each location. One can find the detail information on the metrics in Wang and Ding (2008) and Wang et al. (2011). These metrics have been proven to be a very useful tool for gauging the performance of current models in simulating the annual variation in global monsoon precipitation (Lee et al. 2010; Wang et al. 2011). The metrics are also applicable to studies on the centennial variation of monsoon precipitation in the last millennium using a coupled ocean-atmosphere model (Liu et al. 2009, 2012) and modern dynamics (Hsu et al. 2011; Wang et al. 2012).

The simple composited monthly mean CMAP and GPCP precipitation data are used as observations in this section. Based on the models' performance in simulation of the GM metrics, we selected some best models for further assessment of future changes.

\subsection{Annual mean precipitation}

The CMIP5 20 CGCMs' MME well reproduces the observed features of annual mean precipitation including the major tropical oceanic convergence zones, the major precipitation zones in the extra-tropical Pacific and Atlantic storm track, and remarkable longitudinal and latitudinal asymmetries (Fig. 1a). In general, models tend to produce double ITCZ in the eastern Pacific. A difference map between the observation and MME simulation (not shown) indicates that the
MME tends to underestimate precipitation over the Eastern Indian Ocean, the Bay of Bengal, the equatorial western Pacific, and tropical Brazil, but overestimate precipitation over the Maritime Continent, Philippines, and the high-elevated terrains such as the Andes, Sierra Madrea, and the Tibetan Plateau. These biases are common in the state-ofthe-art coupled models (Lee et al. 2010).

To objectively evaluate the models' performance on annual mean precipitation, we calculate the pattern correlation coefficient (PCC) and normalized root mean square error (NRMSE) between the observation and simulation by individual CGCMs and their MME over the global region of $60^{\circ} \mathrm{S}-60^{\circ} \mathrm{N}, 0^{\circ}-360^{\circ} \mathrm{E}$ (Fig. 2a). The NRMSE is the RMSE normalized by the observed standard deviation that is calculated with reference to the global mean. The individual models' PCCs range from 0.76 to 0.89 and NRMSE from 0.51 to 0.89 . The MME is evidently better than individual models in simulating annual mean precipitation with the PCC of 0.91 and the NRMSE of 0.41 .

\subsection{The first and second modes of annual variation}

Following Wang and Ding (2008) we define two annualcycle modes by EOF analysis of the climatological monthly mean precipitation which account for 68 and $15 \%$ of the total annual variation of precipitation, respectively. The first mode represents a solstice global monsoon mode and its spatial pattern can be captured extremely well by the difference between June-July-August-September (JJAS) and December-January-February-March (DJFM) mean precipitation. The second mode represents an equinox asymmetric mode (or spring-fall asymmetric mode) and its spatial pattern can be very well captured by the difference between April-May (AM) and OctoberNovember $(\mathrm{ON})$ mean precipitation. Figure $1 \mathrm{~b}$ and $\mathrm{c}$ shows that the 20 models' MME simulates the first annual cycle mode with a high fidelity and the second annual cycle mode reasonably well. The models tend to underestimate the solstice monsoon mode over the East Asia monsoon region, the South China Sea and Philippine Sea and overestimate the equinox asymmetric mode over most of the Tropics.

Figure $2 b$ and $c$ shows that the CMIP5 models can reproduce the observed first annual cycle mode realistically but they have difficulty in getting the second mode right. The individual models have a PCC from 0.74 to 0.85 and a NRMSE from 0.55 to 0.9 for the first mode and a PCC from 0.55 to 0.78 and a NRMSE from 0.8 to 1.49 for the second mode. The MME is more effective for the first mode than the second mode, since model spread for the second mode is much larger. The MME's PCC is 0.91 (0.78) and the MME's NRMSE is 0.47 (0.79) for the first (second) mode, respectively, over the global region. 


\section{Merged CMAP and GPCP}

The 20 Models' MME
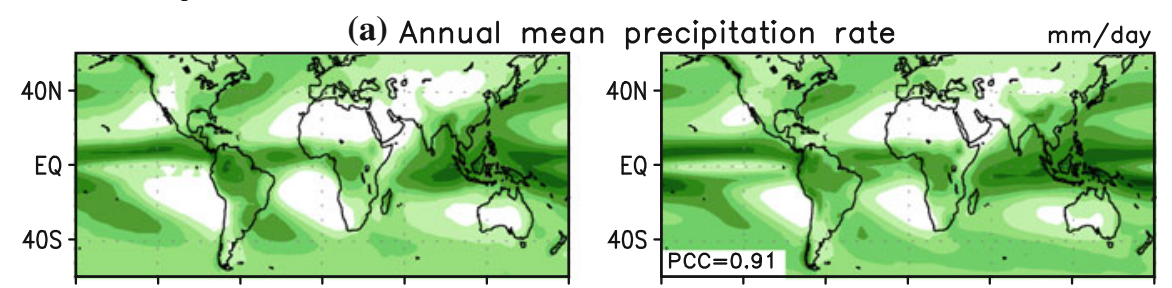

(b) The first annual cycle (solstice mode)
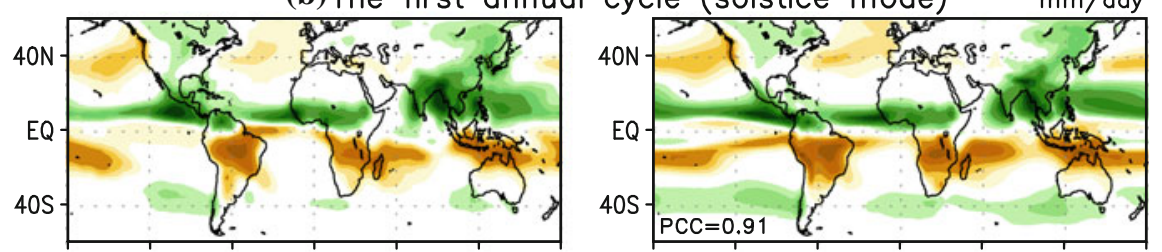

(c) The second annual
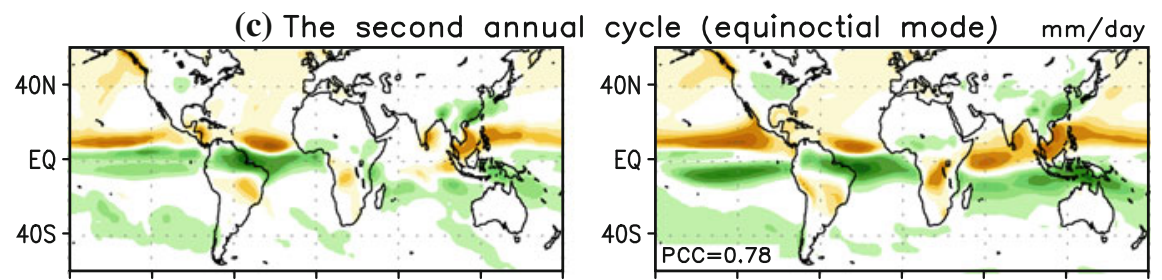

(d) Global monsoon precipitation intensity and domain $\times 0.5$
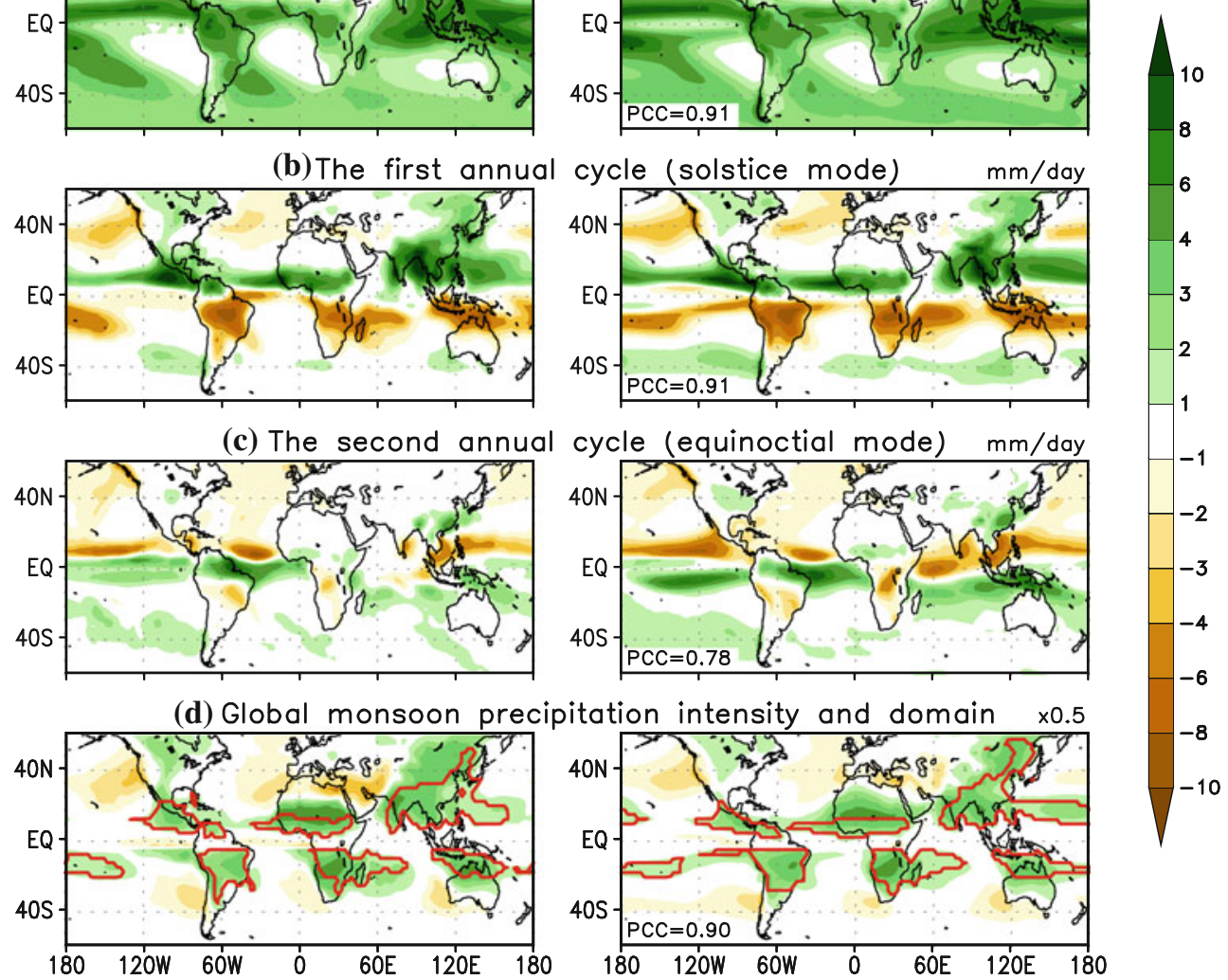

Fig. 1 Comparison of precipitation climatology (1980-2005) between observation (merged CMAP and GPCP) and 20 CGCMs' multi-model ensemble (MME): a annual mean precipitation rate $\left(\mathrm{mm} \mathrm{day}{ }^{-1}\right), \mathbf{b}$ the first annual cycle mode (solstice mode, JJAS minus DJFM), $\mathbf{c}$ the second annual cycle mode (equinoctial asymmetric mode, AM minus $\mathrm{ON}$ ), and $\mathbf{d}$ global monsoon precipitation intensity (non-dimensional) and domain. The global monsoon

precipitation domain (outlined by red contours) in $\mathbf{d}$ is defined by regions where the summer-minus-winter precipitation exceeds $2.5 \mathrm{~mm} \mathrm{day}^{-1}$ and the summer precipitation exceeds $55 \%$ of the annual total, where summer means MJJAS (NDJFM) for the NH (SH). The numbers in the right lower corners indicate pattern correlation coefficient (PCC) between the observed and simulated global patterns $\left(60^{\circ} \mathrm{S}-60^{\circ} \mathrm{N}, 0^{\circ}-360^{\circ} \mathrm{E}\right)$

\subsection{The GM precipitation intensity and domain}

The GM precipitation intensity is defined by the ratio of local summer-minus-winter precipitation to the annual total, where summer means May-June-July-August-September (MJJAS) for the NH and November-DecemberJanuary-February-March (NDJFM) for the SH and winter means NDJFM for the NH and MJJAS for the SH. The GM precipitation domain is defined by the regions where the summer-minus-winter precipitation exceeds $2.5 \mathrm{~mm}$ day $^{-1}$ and the GM precipitation intensity exceeds 0.55 (Wang et al. 2011). The CMIP5 models' MME well captures the GM precipitation intensity and domain (Fig. 1d) except over the Western North Pacific-East Asia monsoon region.

Figure $2 \mathrm{~d}$ shows the PCC and NRMSE between the observed and simulated GM precipitation intensity indicating the MME is very effective for improving the

intensity simulation. The individual models have a PCC from 0.78 to 0.86 and a NRMSE from 0.53 to 0.68 . The MME has the PCC of 0.9 and the RMSE of 0.41 .

\subsection{Best model selection}

Taking into account the significant inter-model spread over their MME, particularly for the second annual cycle mode (Fig. 2), efforts have been made to optimally select some of best models in reproducing GM precipitation during historical run period for the sake of more reliable MME construction and future projection.

The model selection is based on the PCC and signal-tonoise ratio for the annual mean precipitation, the combined first and second annual-cycle modes, and GM precipitation intensity. We combined the PCCs of the first and second annual cycle mode by weighting their fractional-variance 


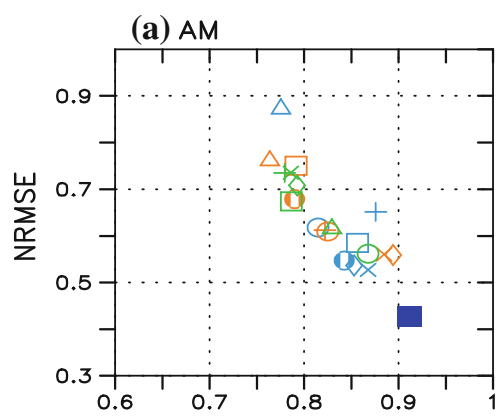

(c) AC 1

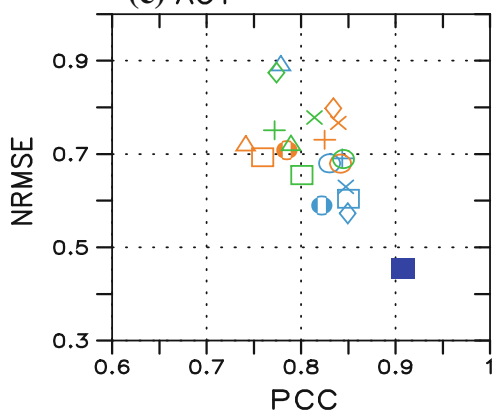

(b) AC2

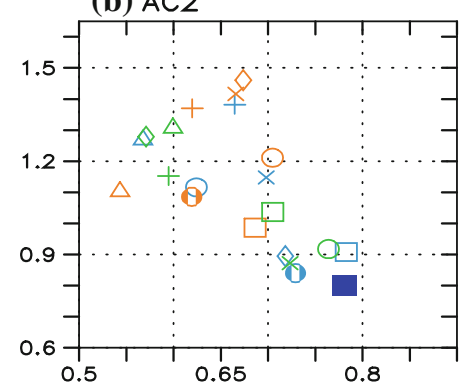

(d) GMPI

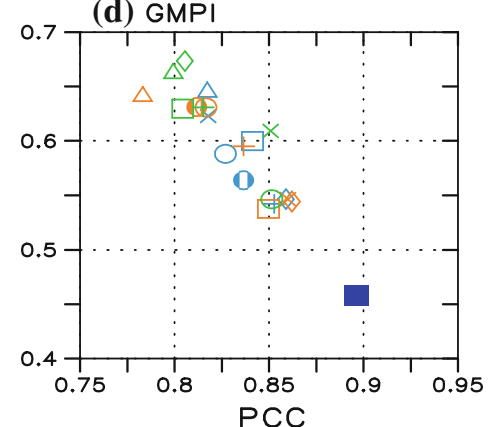

\begin{tabular}{|c|c|c|c|c|c|c|}
\hline \multicolumn{7}{|l|}{ MME } \\
\hline+ ACCESS 1 & $\mathrm{BCC}-\mathrm{CSM} 1$ & $\square$ CanESM2 & $\times \cos M 4$ & $\triangle C N R M-C M 5$ & $\triangle C S I R O-M K 3$ & O FGOALS - g2 \\
\hline+ GFDL-CM3 & GFDL-ESM2M & $\square$ GISS-E2 & $\times$ HadGEM $2-C C$ & $\diamond$ HadGEM2-ES & $\triangle I N M C M 4$ & O IPSL-LR \\
\hline$+I P S L-M R$ & MIROC5 & $\square$ MIROC-ESM & $\times$ MPI-ESM & $\diamond M R I-C G C M 3$ & $\triangle$ NorESM $1-M$ & \\
\hline
\end{tabular}

Fig. 2 Performance of CGCMs and their MME on precipitation climatology (1980-2005): a annual mean precipitation, b the solstice mode (AC1, JJAS minus DJFM), $\mathbf{c}$ the equinoctial asymmetric mode (AC2, AM minus ON), and $\mathbf{d}$ global monsoon precipitation intensity (GMPI). The abscissa and ordinates are pattern correlation coefficient

contributions to the annual variation ( 0.68 and 0.15 respectively), following Lee et al. (2010). The signal-tonoise ratio is defined by the ratio of the absolute value of the MME (as a signal) to inter-model standard deviation against the MME (as a noise). The averaged signal-to-noise ratio tends to decrease as the number of models used for the MME increases, while the averaged PCC is the highest when the four or five best models are used for the MME (Figure not shown). Since the fifth best model (ACCESS1) did not participated in the CMIP3, we select four best models whose MME has a better skill with much less uncertainty than the 20-model's MME as well as other subsets of MME for capturing GM precipitation climatology. The best four models are CanESM2, CNRM-CM5, HadGEM2-ES, and MIROC5. Figure 3 compares the PCCs and threat score of individual models, the 20-models' MME and the best four models' MME (B4MME, hereafter). The threat score is defined by the number of hit grids divided by the sum of hit, missed, and false-alarm grids (Wang et al. 2011).

In Fig. 3, we also evaluate performance of the 19 CMIP3 models in simulating GM precipitation. The four modeling groups that were selected for the best models in the CMIP5 also participated in the CMIP3. The models
(PCC) and domain-averaged RMSE normalized by the observed spatial standard deviation (NRMSE), respectively. The domain used is $60^{\circ} \mathrm{S}-60^{\circ} \mathrm{N}, 0^{\circ}-360^{\circ} \mathrm{E}$. The observed precipitation data were obtained from the merged CMAP and GPCP data

corresponding to CanESM2, CNRM-CM5, HadGEM2-ES, and MIROC5 in the CMIP5 are CCCMA-CGCM3.1-t63, CNRM-CM3, HadGEM1, and MIROC3-2-HR in the CMIP3. All four models in the CMIP3 were forced with historical greenhouse gases as well as the time varying ozone, sulfate and volcanic aerosols, and solar output. It is noted that considerable improvement from the CMIP 3 to CMIP5 models were made including increase in resolution and more complete treatment of the atmospheric chemistry. In particular, CanESM2 and HadGEM2-ES are Earth System Models incorporating with interactive prognostic aerosols, chemical elements, and dynamical vegetation (Taylor et al. 2012).

The GM assessment is applied to the CMIP3 19 models' MME and the four selected models' MME (CMIP3 4MME hereafter). To calculate the four skill measures, climatology was used from 1980 to 1999 for both CMIP3 models and observation. It is shown that there are some improvements from the CMIP3 to CMIP5 in the skill measures. In particular, the CMIP5 B4MME better simulate GM precipitation intensity and domain than the CMIP3 4MME (Fig. 3b). The signal-to-noise ratio for the GM precipitation climatology is also larger in the CMIP5 B4MME than the CMIP3 4MME (not shown). 

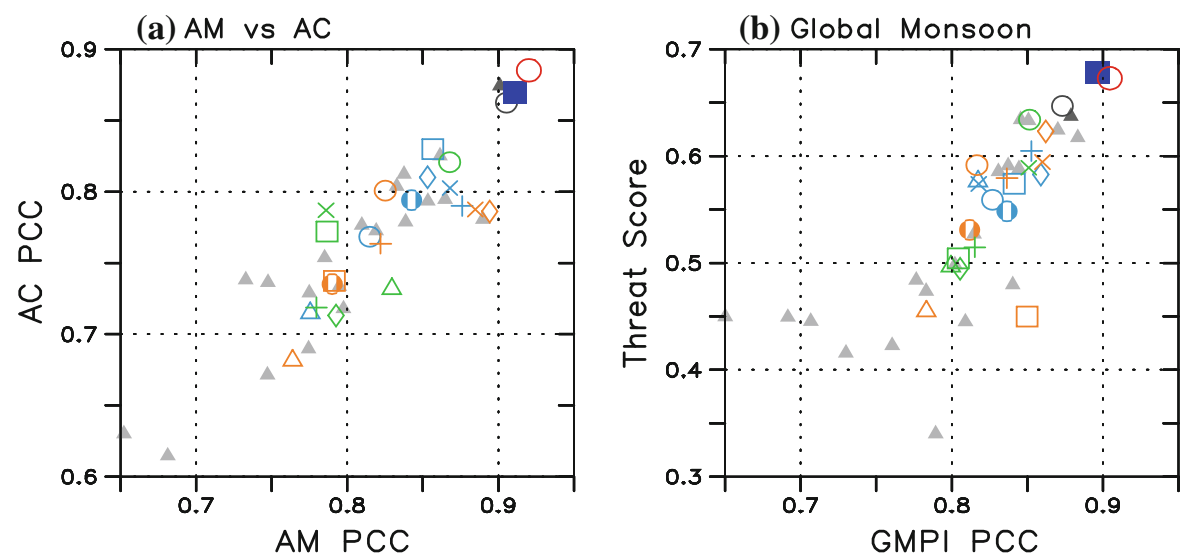

\begin{tabular}{|c|c|c|c|c|c|c|}
\hline MME & O B4MME & $\triangle$ CMIP3-MME & O CMIP3-4MME & $\triangle$ CMIP3-Individ & ual & \\
\hline+ ACCESS1 & BCC-CSM 1 & $\square$ CanESM2 & $\times \operatorname{ccsm} 4$ & $\triangle \mathrm{CNRM}-\mathrm{CM} 5$ & $\Delta \mathrm{CSIR}$ & $-g 2$ \\
\hline + GFDL-CM3 & GFDL-ESM2M & $\square$ GISS-E2 & $\times$ HadGEM2 $-\mathrm{CC}$ & $\diamond$ HadGEM2-ES & $\triangle I N M C M 4$ & 0 IPSL-LR \\
\hline+ IPSL-MR & MIROC5 & $\square$ MIROC-ESM & $\times$ MPI-ESM & $\triangle \mathrm{MRI}-\mathrm{CGCM} 3$ & $\triangle$ NorESM1-M & \\
\hline
\end{tabular}

Fig. 3 Overall assessment of the $20 \mathrm{CGCMs,}$ their MME, and the best four models' MME (B4MME): a PCCs of annual mean (abscissa) versus annual cycle (ordinate), and b PCC of the climatological GMPI (abscissa) versus threat score of monsoon domain (ordinate). The best four models are CanESM2, CNRM-CM5,

\section{Future change of GM precipitation}

This section discusses future change of GM precipitation by comparing climatological means during the historical run period (1980-2005) and the RCP4.5 run period (2070-2095) using the CMIP5 B4MME selected in Sect. 3. Changes estimated by the difference between the $20 \mathrm{C} 3 \mathrm{M}$ (1980-1999) and SRESA1B (2070-2095) simulation in the CMIP3 4MME are also compared.

\subsection{Monsoon domain and monsoonality}

Figure 4a compares the GM precipitation domain between the historical and RCP4.5 run. The B4MME projects only $4.6 \%$ increase of GM domain in future, which is less than the standard deviation of inter-model spread (i.e. model uncertainty) as well as the B4MME's bias over the observed domain. The monsoon domains will not change appreciably over land (2.6\% increases) except for the Asia monsoon but will increase over oceanic monsoon regions by $6.3 \%$. The land monsoon domain over Asia tends to expand westward with $10.6 \%$ increase in monsoon extent.

The monsoonality defined by the percentage of local summer rainfall will change significantly (Fig. 4b). Here the local summer refers to MJJAS (NDJFM) for the NH (SH). Stippling in Fig. 4b indicates area where the magnitude of the change in the monsoonality of the B4MME exceeds the uncertainty measured by the standard deviation of inter-model spread against the B4MME. The contribution of local summer rainfall to annual mean precipitation will increase over most subtropical regions and decrease
HadGEM2-ES, and MIROC5. For comparison, assessment was also made for the 19 CMIP3 models and their MME. The MME was also made using four models of CMIP3 corresponding to the best four models of CMIP5 (i.e., CMIP3-4MME)

over extratropical regions. An increase of the percentage of local summer rainfall is expected over most of the observed GM domains (red contours) including some parts of the Western North Pacific-East Asia, Africa, Australia, South America monsoon, while a decrease is projected over the South Asia and North American monsoon region. It is interesting to note that an increase is projected over many part of arid or semiarid region (grey contour in Fig. 4b). The arid and semiarid regions are defined as regions where summer precipitation rate is less than $1 \mathrm{~mm} \mathrm{day}^{-1}$. In addition, the changes are more prominent over the $\mathrm{NH}$ than the SH. It is further noted that spatial distribution of the projected changes by the 20-models' MME is very similar to that by the B4MME although the amplitude of its change is less and its uncertainty (inter-model spread) is much larger.

\subsection{Annual mean and annual range of GM precipitation}

The CMIP5 B4MME projects significant increases in annual mean precipitation over most parts of the globe including the entire Asian monsoon region, most extratropical regions, and the equatorial Pacific Ocean. Remarkable decreases are shown over South America, most parts of the SH oceanic regions, and some parts of the Eastern North Pacific and Eastern North Atlantic Ocean (upper panel of Fig. 5a). The projected changes by the CMIP3 4MME are also presented in Fig. 5a (lower panel). In general, the CMIP3 projections well agree with the CMIP5 results. However, there are several differences. First, the CMIP5 projects a less 'wet-get-wetter and 
Fig. 4 Change of GM precipitation domain and percentage of local summer rainfall: a the monsoon domain in the observation (mid-blue shading), the B4MME historical simulation (black solid line), and RCP45 simulation (red dashed line). The period used to determine the monsoon domain is from 1980 to 2005 for the observation and historically simulation and from 2070 to 2095 for the RCP45 simulation. The definition of monsoon domain is the same as in Fig. 1 and the dry regions (outlined by grey) have summer precipitation rate $<1 \mathrm{~mm}$ day $^{-1}$. The merged Global Precipitation Climatology Project/Climate Prediction Center Merged Analysis of Precipitation data were used to determine the monsoon and dry regions. $\mathbf{b}$ The corresponding future changes of percentage of local summer rainfall. Changes are given for the RCP 45 simulation for the period 2070-2095 relative to historical simulation for the period 1980-2005 in CMIP5. Stippling denotes areas where the magnitude of the B4MME exceeds the standard deviation of inter-model spread (a) Global monsoon precipitation domain

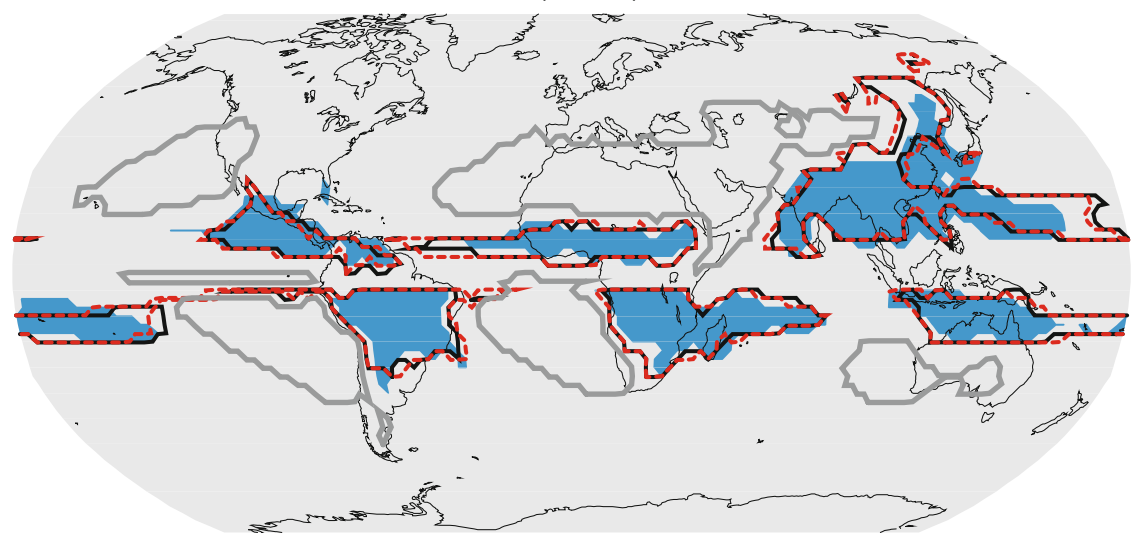

(b) Percentage of local summer rainfall
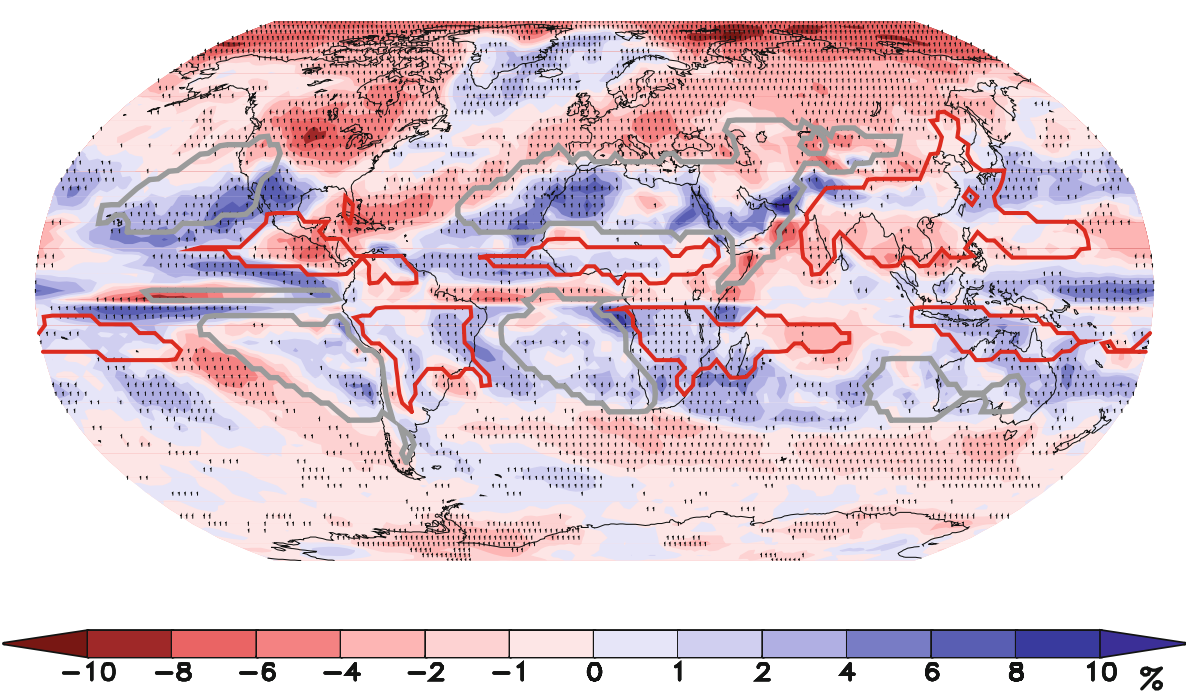

dry-get-drier' pattern than the CMIP3 does. Second, the CMIP5 projects a larger increase in annual mean precipitation over the entire Asian monsoon region with less uncertainty. Third, the CMIP3 projects much larger decrease of the North American monsoon precipitation than the CMIP5. Finally, the center of increased precipitation over the equatorial Pacific is located further to the east in CMIP5 than CMIP3. The differences may be related to the changes in SST mean field. It is noted that the center of SST mean change in the CMIP5 is shifted eastward compared to the CMIP3 (not shown). Further analysis is necessary for the causes of the differences.

Both CMIP5 and CMIP3 models predict amplification of global monsoon rainfall in future (Fig. 5b). In particular, significant increases of the annual range are seen over the South Asian monsoon region, South African monsoon region, and subtropical Pacific and Atlantic Oceans while reduced annual range is evident over the North American monsoon region and many part of North America.
It is important to note that there will be a more prominent east-west asymmetry (Eastern Hemisphere monsoon gets more precipitation and western Hemisphere monsoon get less) and north-south asymmetry (NH monsoon gets more precipitation and $\mathrm{SH}$ monsoon gets less) in global monsoon precipitation. The Eastern Hemisphere monsoon includes the African and Asian-Australian monsoon while the Western Hemisphere monsoon includes the American monsoons.

It should be mentioned that there is no guarantee that the B4MME will produce more reliable future projections in regional scales in comparison with all models' MME (Schaller et al. 2011). To this end, we also investigated future projects using all CMIP5 models' MME for annual mean and range of global precipitation. Figure 6 shows that the spatial distribution of future change estimated by using the all models' MME is almost the same as that estimated by the B4MME. However, the all models' MME have much larger uncertainty (in other word, inter-model spread) than the B4MME. 
(a) Annual Mean

(b) Annual Range

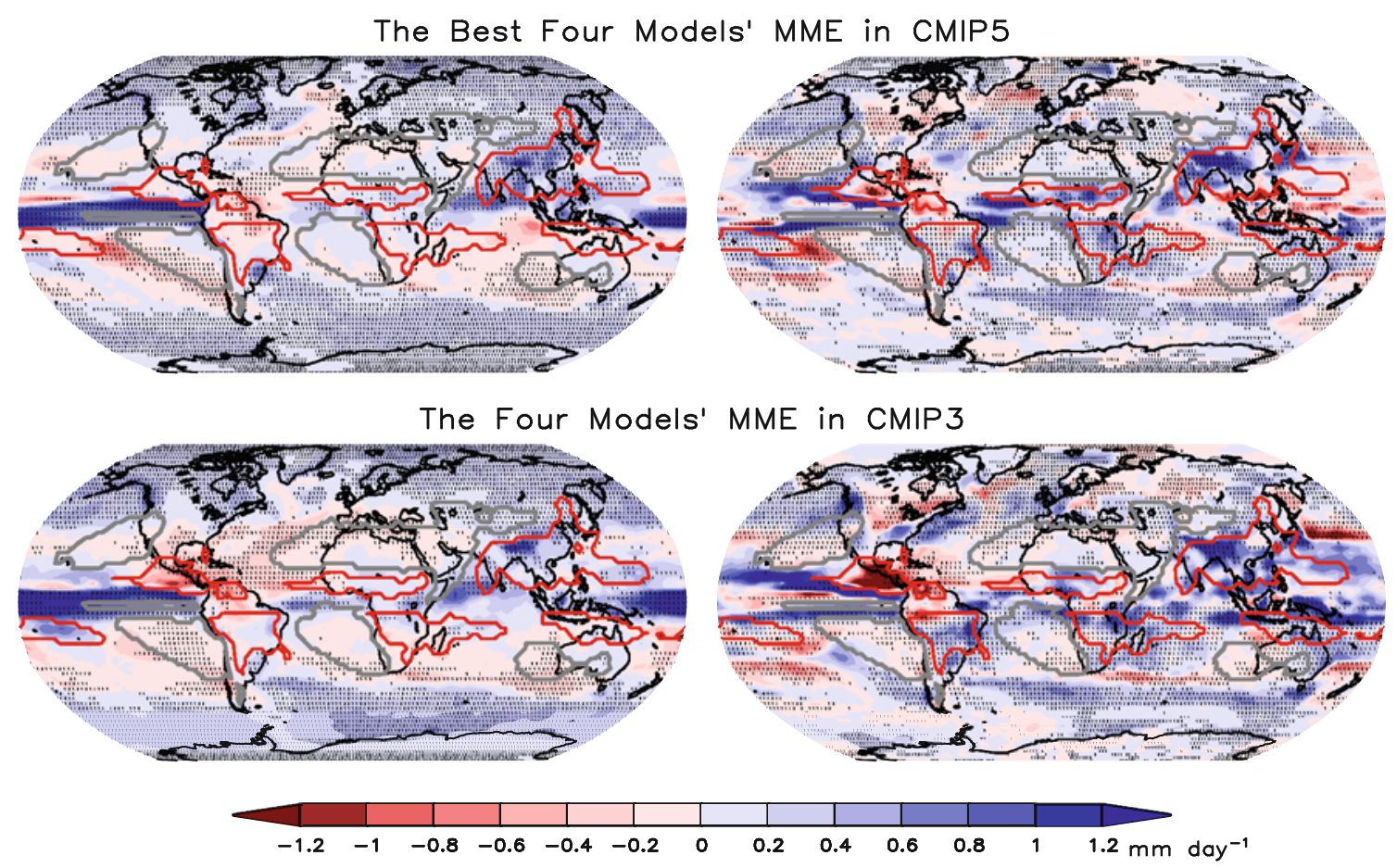

Fig. 5 Changes in a annual mean precipitation and $\mathbf{b}$ the annual range of precipitation. The annual range is defined as absolute value of JJAS minus DJFM mean precipitation rate. Changes are given for the RCP 45 (SRESA1B) simulation for the period 2070-2095 relative

to historical simulation for the period 1980-2005 (1980-1999) in CMIP5 (CMIP3). The B4MME is used for both CMIP5 and CMIP3. Period is the same as in Fig. 4. Monsoon and dry domain are defined the same as in Figs. 1 and 4

\subsection{Summer monsoons: DJF and JJA}

We further investigate changes in precipitation during DJF and JJA projected by the CMIP5 B4MME and CMIP3 4MME (Fig. 7). During austral summer, both CMIP5 and CMIP3 MME project an increase in monsoon precipitation over the Southern Africa and northern and southeast Australia (Fig. 7a). However, CMIP3 projects a slight increase of precipitation but the CMIP5 predicts significant decrease of precipitation over the South American monsoon region. During northern summer, both CMIP5 and CMIP3 MME project a significant increase of monsoon precipitation over the Asian-Western North Pacific monsoon region and remarkable decrease of precipitation over the North American monsoon and Venezuelan monsoon regions (Fig. 7b). This contrasting feature is more significant in the CMIP5 projection. Over the West African monsoon region, the CMIP5 expects a more significant increase of precipitation than the CMIP3. The significant increase of summer precipitation over the entire Asian monsoon region is accompanied by the decrease of precipitation over the Sahara desert and most part of Europe, suggesting the monsoon-desert coupling (Hoskins and Rodwell 1995) is in action. The remarkable decrease of summer precipitation over the North American monsoon region may be related to the significant increase of precipitation over the eastern equatorial Pacific.

Similar to the CMIP3 projection of surface temperature (Meehl et al. 2007b), the CMIP5 B4MME projects (1) increased land-ocean thermal contrast, (2) increased interhemispheric thermal contrasts and (3) an El-Nino type warming that reduced SST gradient across the equatorial Pacific under the global warming in both boreal winter and summer (Fig. 8). Along with temperature increase, there is an overall increase in 850 -hPa specific humidity everywhere (Fig. 9a, c). However, the increase of moisture is spatially uneven and the pattern is extremely similar to the precipitation change (Fig. 7) rather than to the temperature change (Fig. 8), suggesting that both monsoon rainfall and low-level humidity changes are associated with the same large scale circulation changes (Fig. 9b, d) under anthropogenic global warming. Figure 9 also indicates that atmospheric moisture will be increased more over the monsoon domains than dry regions in both boreal winter and summer.

The changes in circulation during northern summer shown in Fig. 9d are characterized by a salient decreasing SLP over the northwestern Eurasian continent and North Africa; correspondingly, a giant, enhanced cyclonic circulation dominating the Eurasia and North Africa, which, on 
(a) Annual Mean

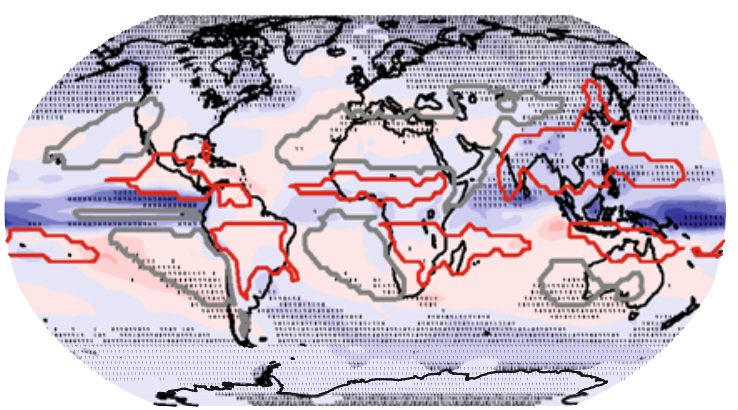

(b) Annual Range

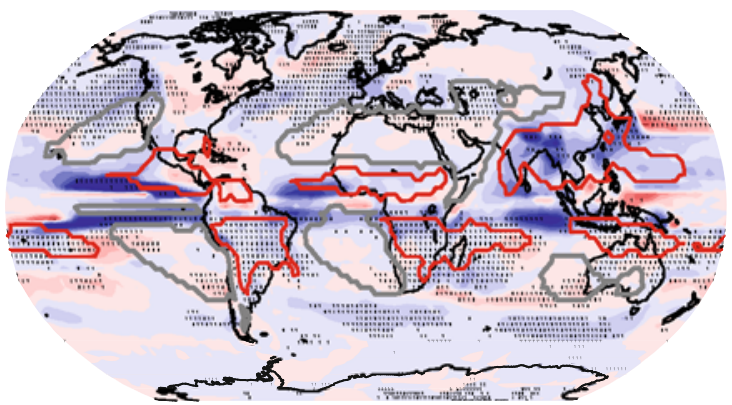

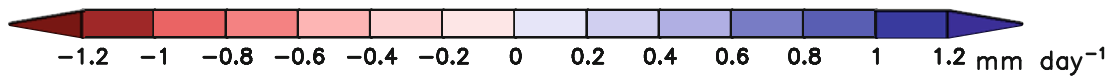

Fig. 6 Same as Fig. 5 except using all CMIP5 models' MME

(a) DJF

The Best Four Models' MME in CMIP5

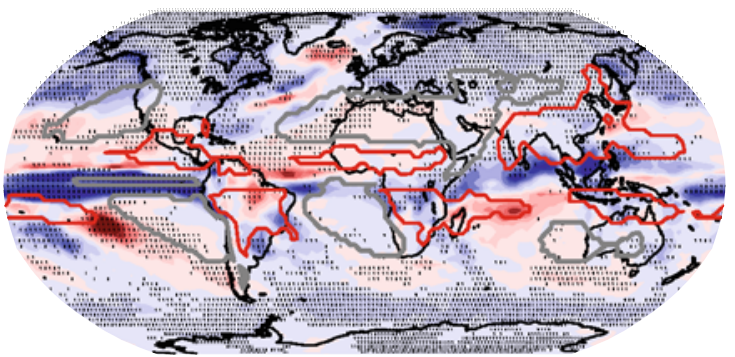

The Four Models' MME in CMIP3
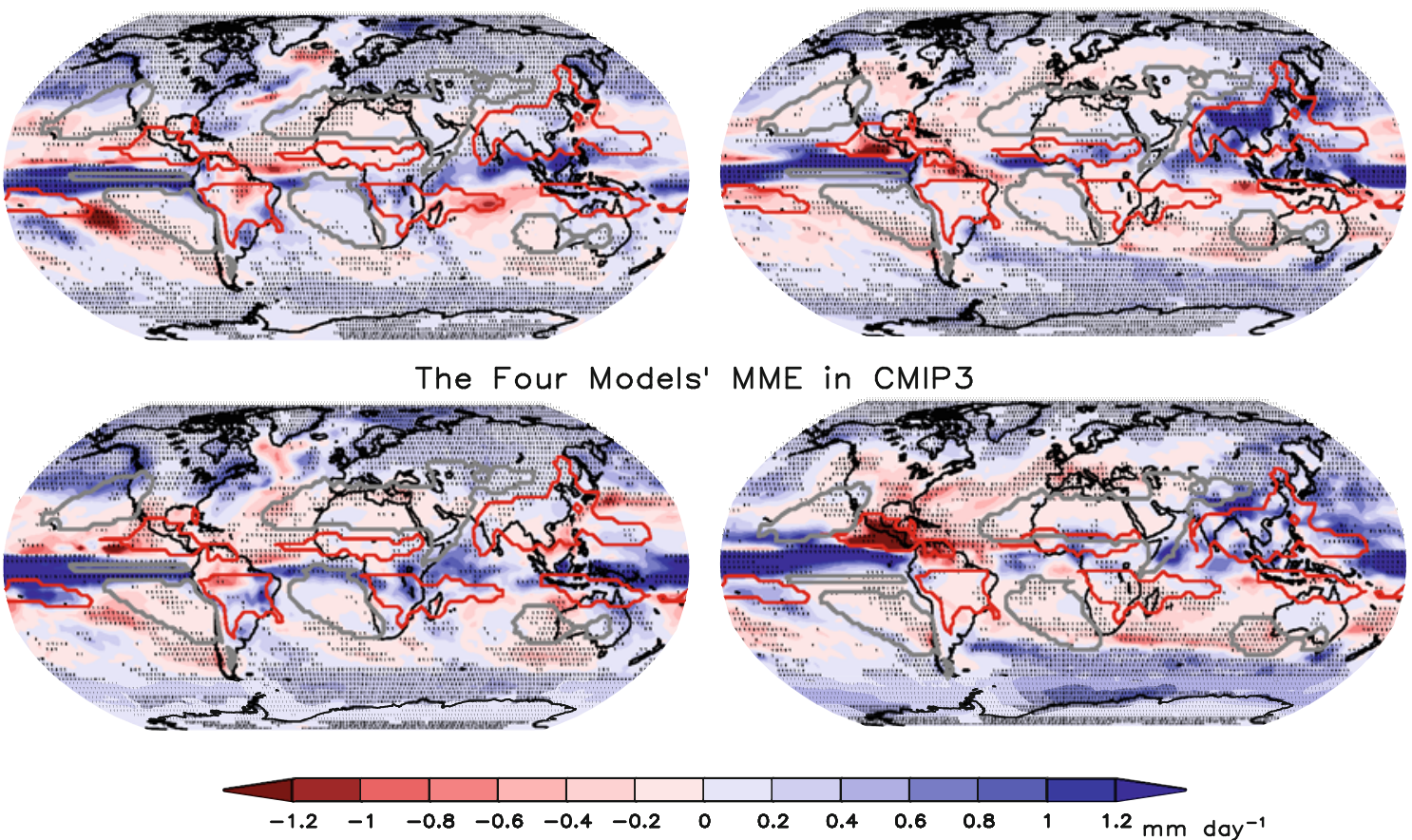

Fig. 7 Changes in monsoon precipitation for a boreal winter (DJF) and $\mathbf{b}$ summer (JJA). Changes are given for the RCP 45 (SRESA1B) simulation for the period 2070-2095 relative to historical simulation for the period 1980-2005 in CMIP5 (CMIP3). Stippling denotes areas

one hand, generates moist westerly and southwesterly monsoon flows into Sahal, India and East Asia, increasing West African and Asian monsoons; on the other hand, the giant low pressure also brings dry continental air to central Asia and Europe, decreasing precipitation there. It is also noted that the North Pacific subtropical High and North Atlantic subtropical Highs tend to shift westward. The westward shift of the western Pacific subtropical High enhances moisture transport into East Asia, but the where the magnitude of the best 4-model ensemble mean exceeds the inter-model standard deviation. Period is the same as in Fig. 5. Monsoon and dry domain are defined the same as in Fig. 5

westward shift of the North Atlantic subtropical High suppresses convection over the Caribbean Sea-Gulf of Mexico and Mexican and Venezuelan monsoon regions.

\subsection{Seasonality: onset and withdrawal}

The NH summer monsoon commences in May and withdraws largely in September (Wang and LinHo 2002). Therefore, an increasing precipitation in May and 


\section{Surface Temperature}

(a) DJF
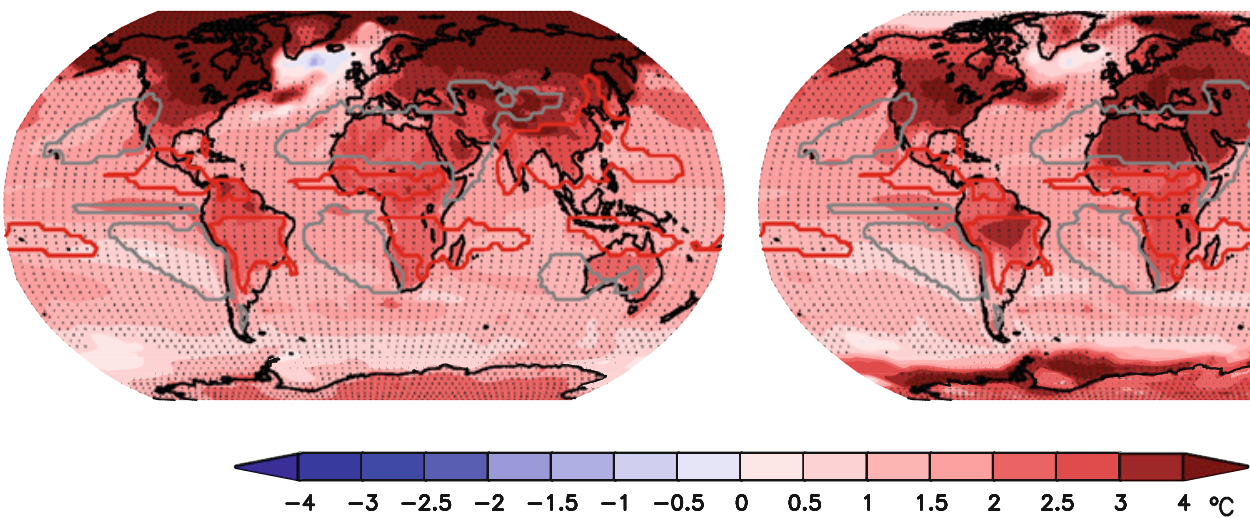

(b) JJA

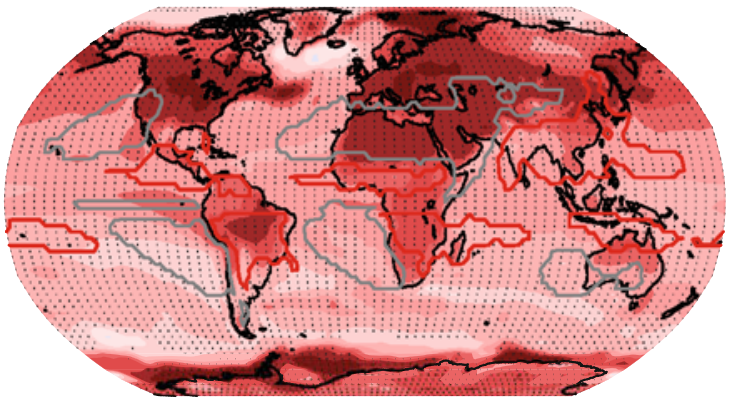

${ }^{\circ} \mathrm{C}$

Fig. 8 Changes in surface temperature for a boreal winter and $\mathbf{b}$ summer. The best four models' MME of CMIP5 is used

(a) DJF

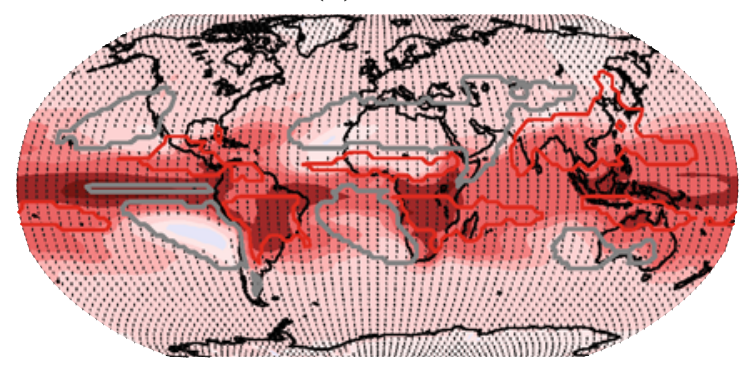

(b) JJA

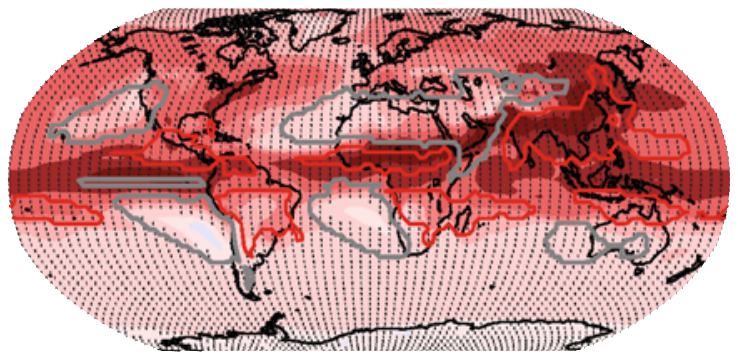

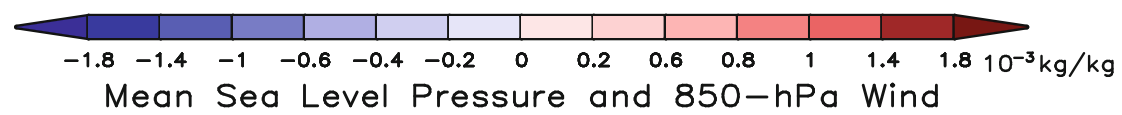

(c) DJF

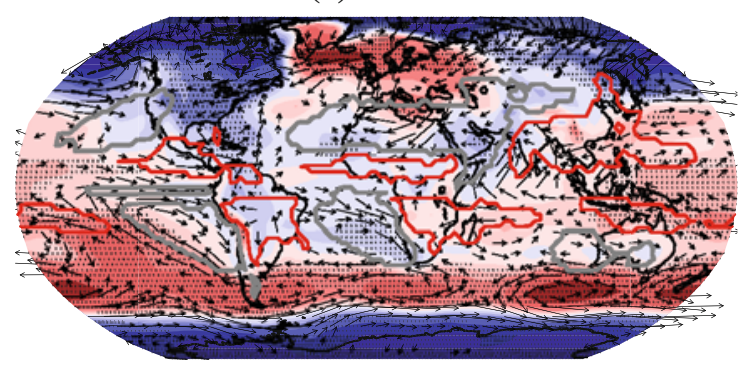

(d) JJA

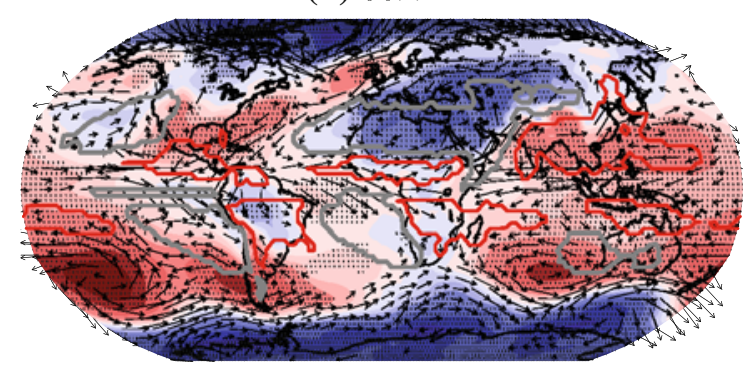

$\overrightarrow{1 \mathrm{~m} / \mathrm{s}}$

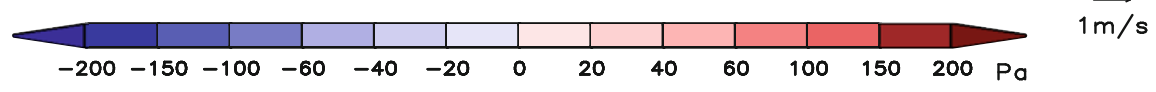

Fig. 9 Changes in 850-hPa specific humidity (upper) for a boreal winter and c summer and mean sea level pressure (shading) and 850-hPa wind (lower) for $\mathbf{b}$ boreal winter and $\mathbf{d}$ summer

September means an earlier onset and later withdrawal. Figure 10 indicates that the $\mathrm{NH}$ monsoon onset will advance and withdrawal will delay, suggesting lengthening of summer monsoon period, particularly over the Asian monsoon region. Over the North American monsoon region, September precipitation is seen to be substantially increased but changes in May precipitation is marginal. Over most of the $\mathrm{NH}$ high latitude $\left(>50^{\circ} \mathrm{N}\right)$, lengthening of summer rainy period is also expected, while precipitation in May and September will slightly decrease over some part of dry region and some part of the NH oceans. Results also indicate that the $\mathrm{NH}$ extratropical region with 
(a) May

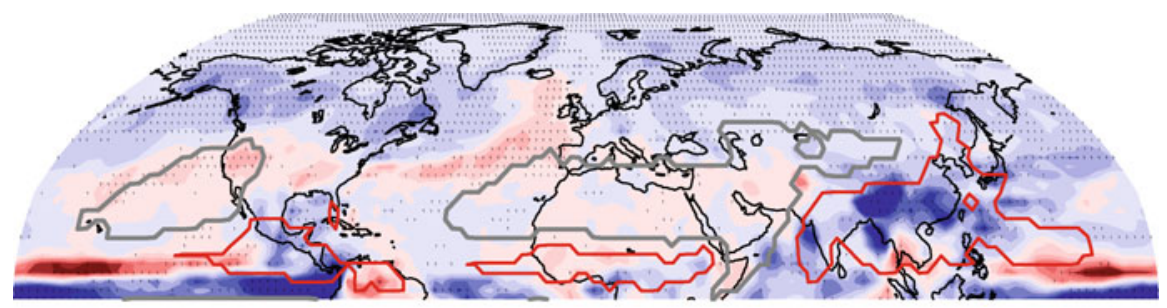

(b) September
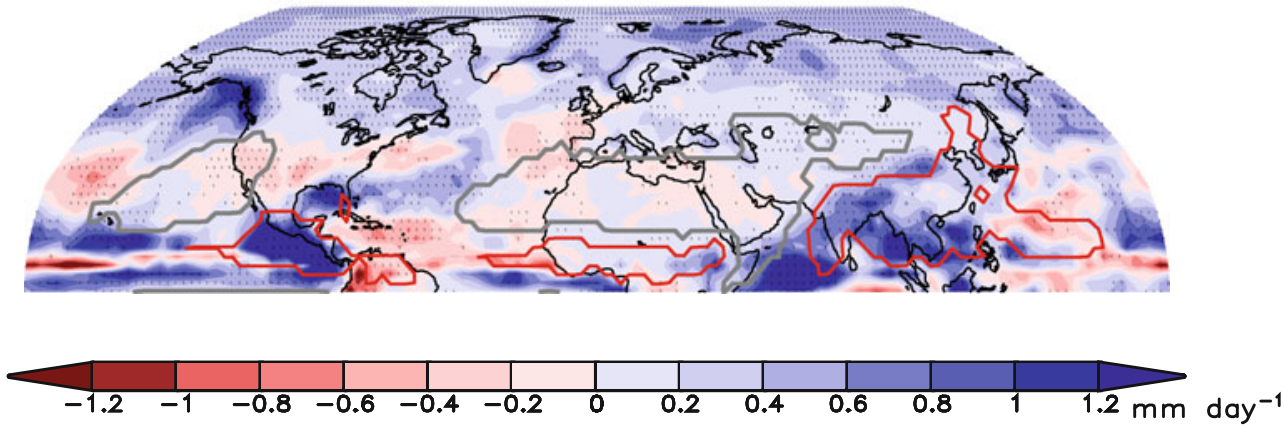

Fig. 10 Change in mean precipitation rates in a May and b September over the northern hemisphere (NH) by the CMIP5 B4MME

Mediterranean climate characterized by warm/hot and dry summers and mild/cool and wet winters will expect lengthening of winter rainy period.

\section{Transient trends}

\subsection{GM precipitation}

This section discusses transient trends of GM precipitation obtained from the B4MME from 1850 to 2100 along with the RECG precipitation from 1900 to 2008. The anomalies were obtained against climatology from 1980 to 2005. In Fig. 11a, the reconstructed Global summer monsoon precipitation obtained from the RECG exhibits a gradual increasing trend from 1900 to 2008 superimposed by large interannual to interdecadal variations. In particular, it exhibits a slight decreasing trend from 1950 to 1990 and then an increasing trend from 1990 associated with strong interdecadal variation. The B4MME realistically captures the trend and interdecadal variation for the recent 50 year period (1955-2005), whereas disagrees with the trend shown by RECG data during the first half of the twentieth century. The later discrepancy may be also due to lack of observation over the ocean but we are not certain. Nevertheless the agreement in the latter half of the twentieth century seems encouraging and may suggest the MME has some capability of capturing the observed variation because the precipitation data after 1979 is considered reliable. Along with a strong warming trend of the global mean surface temperature (green long-dashed line), the simulated GM precipitation gradually increases superimposed by interannual to decadal variation.

The increasing trend of the global mean precipitation is almost the same as that of the GM precipitation with a gradual increase from 1990 to 2100 . The global mean precipitation anomaly reaches about $0.12 \mathrm{~mm} \mathrm{day}^{-1}$ at year of 2100 against climatology of 1980-2005. We should also note that the trends of GM precipitation and global mean precipitation are not consistent with the global mean temperature trend in the period before 1980. This may suggest that the consistent trends between the global mean temperature and global precipitation take place only during recent rapid warming (also data are reliable) and in future continuing rapid warming period.

Figure 12 further indicates that both the global mean and the GM precipitation will increase $0.057 \mathrm{~mm} \mathrm{day}^{-1}$ per Kelvin global mean temperature rise that is corresponding to 1.9 and $1.3 \%$ increase per Kelvin global mean temperature rise for the global mean and GM precipitation, respectively, against the 1980-2005 climatology (2.94 and $4.28 \mathrm{~mm} \mathrm{day}^{-1}$, respectively). It is to note that the CMIP5 B4MME likely has larger response to natural forcing and aerosols than the CMIP3 4MME as suggested by Yeh et al. (2012). The global mean temperature anomaly reaches at $2.2 \mathrm{~K}$ in the CMIP5 B4MME (Fig. 10) but $3.4 \mathrm{~K}$ in the CMIP3 4MME (not shown). However, response of precipitation is larger in the CMIP5 than the CMIP3. 

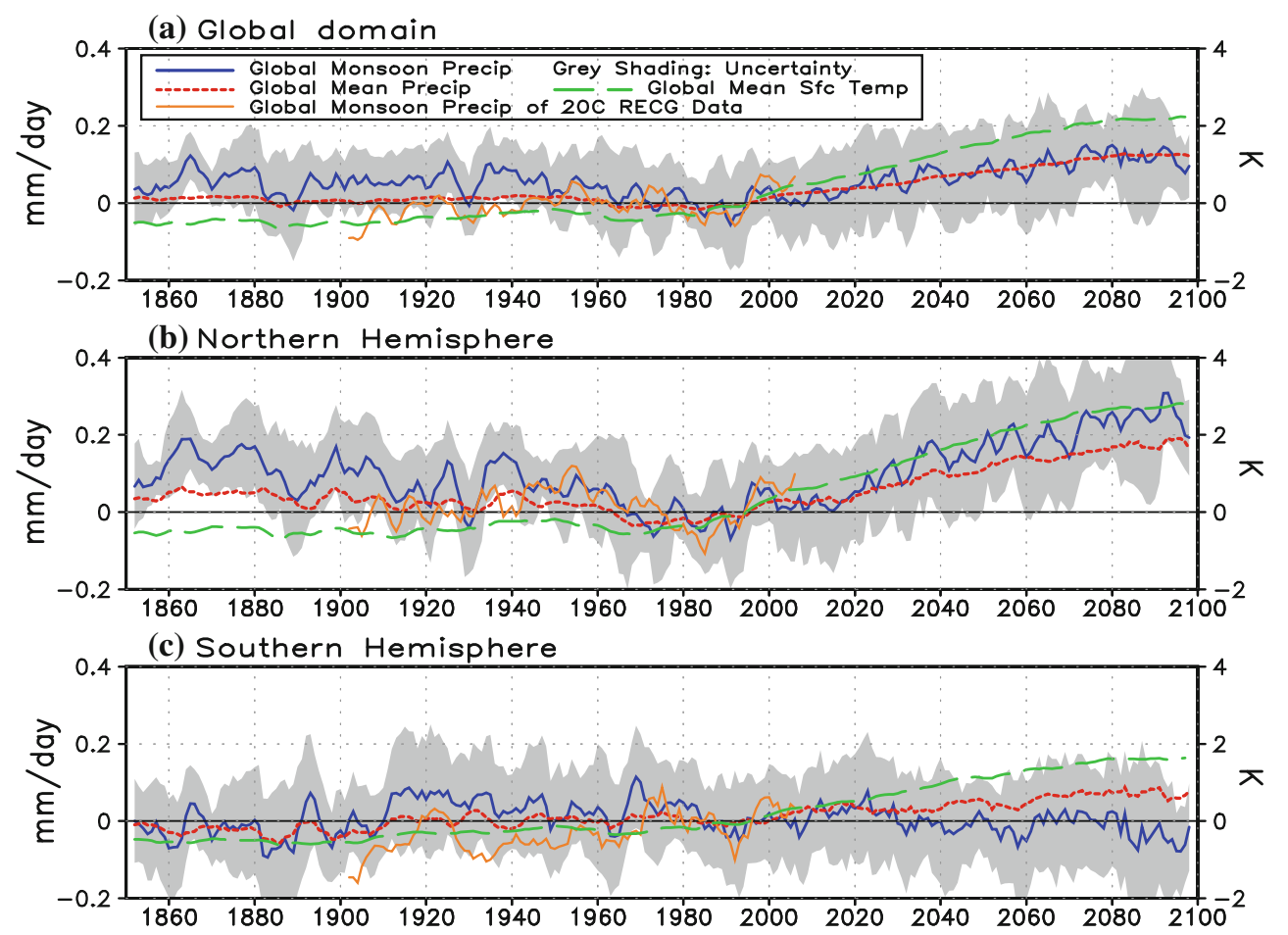

Fig. 11 Transient response of the global monsoon precipitation rate (blue) versus global mean precipitation rate (red) for a global domain, b $\mathrm{NH}$, and c $\mathrm{SH}$ obtained from the best four models' MME for the historical run period (1850-2005) and the RCP45 run period (2006-2100) MME's uncertainty for global monsoon precipitation was obtained from 1 standard deviation of individual models departure from MME. The anomaly was obtained from the climatology of 1980-2005. 5-year moving averaging was applied to all time series

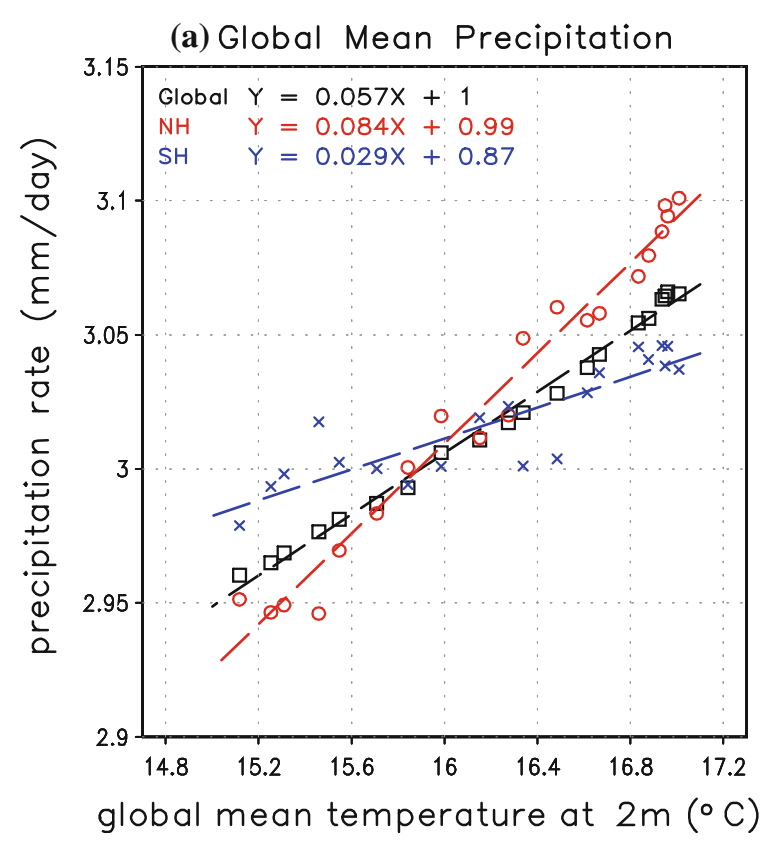

Fig. 12 Scatter diagram showing a area mean and b monsoon precipitation rates as functions of global mean 2 m-air temperature for the period of 2000-2100 in the CMIP5 B4MME over the globe, northern hemisphere, and southern hemisphere, respectively. 5-year

\section{(b) Global Monsoon Precipitation}

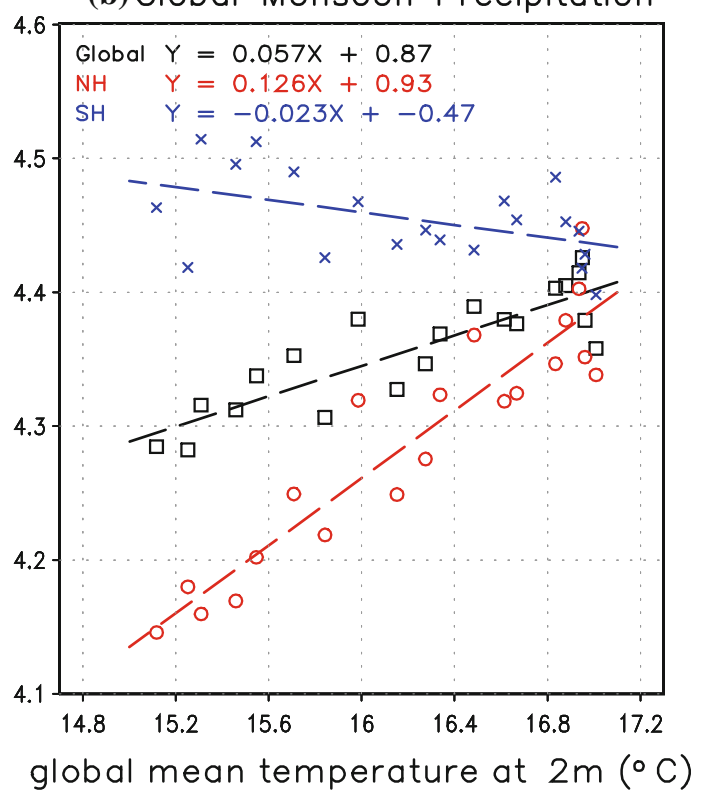

average was applied. The difference between the $\mathrm{NH}$ and $\mathrm{SH}$ slopes is significant at $95 \%$ confidence level for both area mean and monsoon precipitation 
(a) Global Mean Precipitation

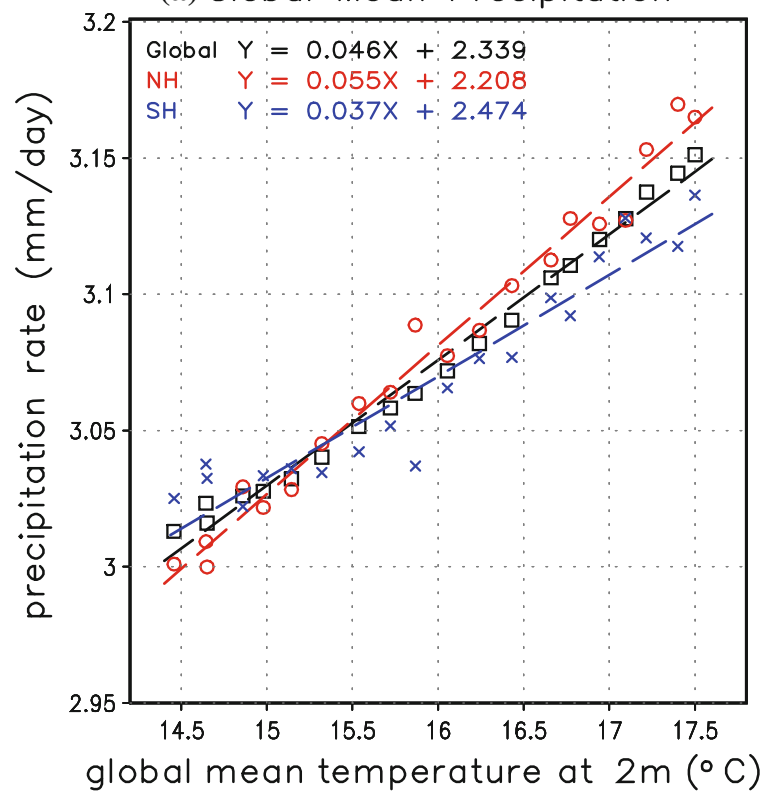

(b) Global Monsoon Precipitation

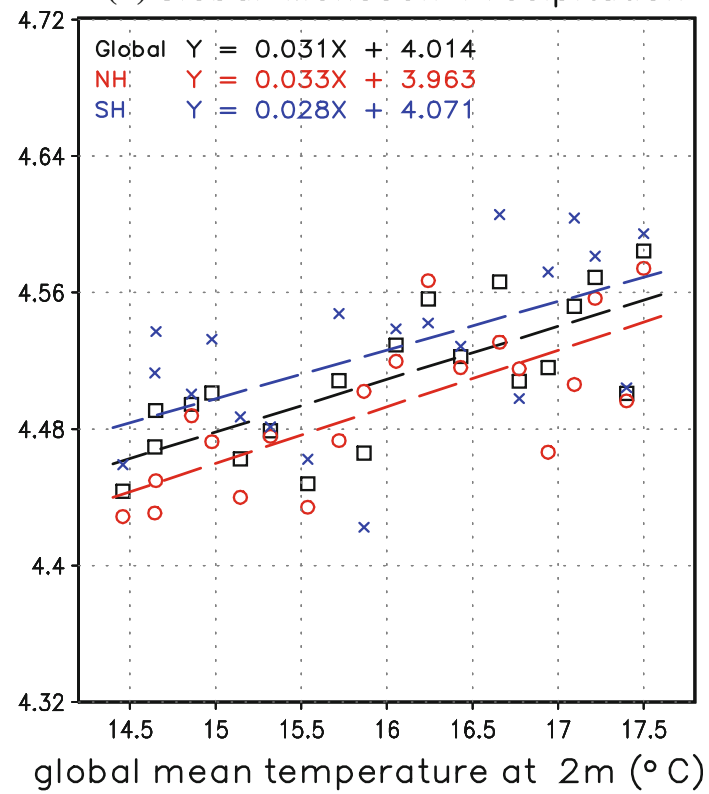

Fig. 13 Same as Fig. 12 except for the CMIP3 4MME. The difference between the NH and SH slopes is significant at $95 \%$ confidence level for $\mathbf{a}$ area mean but not for $\mathbf{b}$ monsoon precipitation

The CMIP3 4MME projects that global mean and GM precipitation will increase by 1.4 and $1 \%$, respectively, per one degree warming (Fig. 12).

It is important to note that changes in monsoon precipitation exhibits huge differences between the $\mathrm{NH}$ and the SH (Fig. 11b, c). The NH monsoon precipitation will be dramatically intensified, reaching $0.2-0.25 \mathrm{~mm} \mathrm{day}^{-1}$ at year of 2100 , a rate slightly faster than the $\mathrm{NH}$ mean precipitation increase. The $\mathrm{NH}$ mean precipitation and monsoon precipitation will increase by 2.8 and $3.1 \%$, respectively, per Kelvin global warming (Fig. 12). In sharp contrast, the SH monsoon precipitation will slightly decrease, although not statistically significant.

Comparison of Figs. 12 and 13 indicate large discrepancies exist between the CMIP 3 and CMIP 5 selected models MME in terms of change of SH monsoon precipitation rates. The CMIP5 B4MME predicts $0.3 \%$ decrease of the SH mean monsoon precipitation per one degree warming (Fig. 12), but the CMIP3 4MME projects $0.6 \%$ increase (Fig. 13).

These projected results are consistent with the monsoon precipitation trends/changes in the recent three decades (1979-2010) detected by Wang et al. (2012) using reliable observations. Wang et al. (2012) found that the NH summer monsoon precipitation has significantly increased over the 1979-2010 period whereas the SH summer monsoon precipitation has no trend. They attributed this difference to the hemispheric thermal contrast change: the $\mathrm{NH}$ warms much more than the SH in the past three decades, which has increased the hemispheric thermal contrast that generates a cross equatorial flow from southern to northern hemisphere which favors intensification of the $\mathrm{NH}$ monsoon but tends to decreases the SH monsoon precipitation increase or offsets the increase due to increasing moisture content. The same hemispheric trend will occur during the twenty-first century warming. This issue will revisit in the next subsection.

The monsoon domain comes across both land and adjacent oceans. One may more concern with the change in the land monsoon precipitation. As shown in Fig. 14, the GM precipitation shows a similar level of increasing trend over both the ocean and land, although over the ocean the monsoon precipitation has a larger variability and uncertainty than that over the land (Fig. 14).

\subsection{Future change of the circulation and thermodynamics}

Changes in circulation are also investigated in terms of the Walker and Hadley Cell strength. Using 20C3M and SRESA1B simulations of 15 CMIP3 CGCMs, Tanaka et al. (2005) showed that Hadley, Walker, and monsoon circulations during boreal summer will be weakened by 9,8 , and $14 \%$, respectively, by the late twenty-first century. In this study, the low-level Walker Cell strength is defined by the negative value of the annual mean of $850-\mathrm{hPa}$ zonal wind (U850) averaged over $10^{\circ} \mathrm{S}-10^{\circ} \mathrm{N}, 150^{\circ} \mathrm{E}-80^{\circ} \mathrm{W}$. The Hadley cell strength is measured by the DJF vertical differential divergence between 200 and $850 \mathrm{hPa}$, averaged over $5^{\circ} \mathrm{S}-$ $10^{\circ} \mathrm{N}, 40^{\circ} \mathrm{E}-80^{\circ} \mathrm{W}$. In comparison with precipitation change 


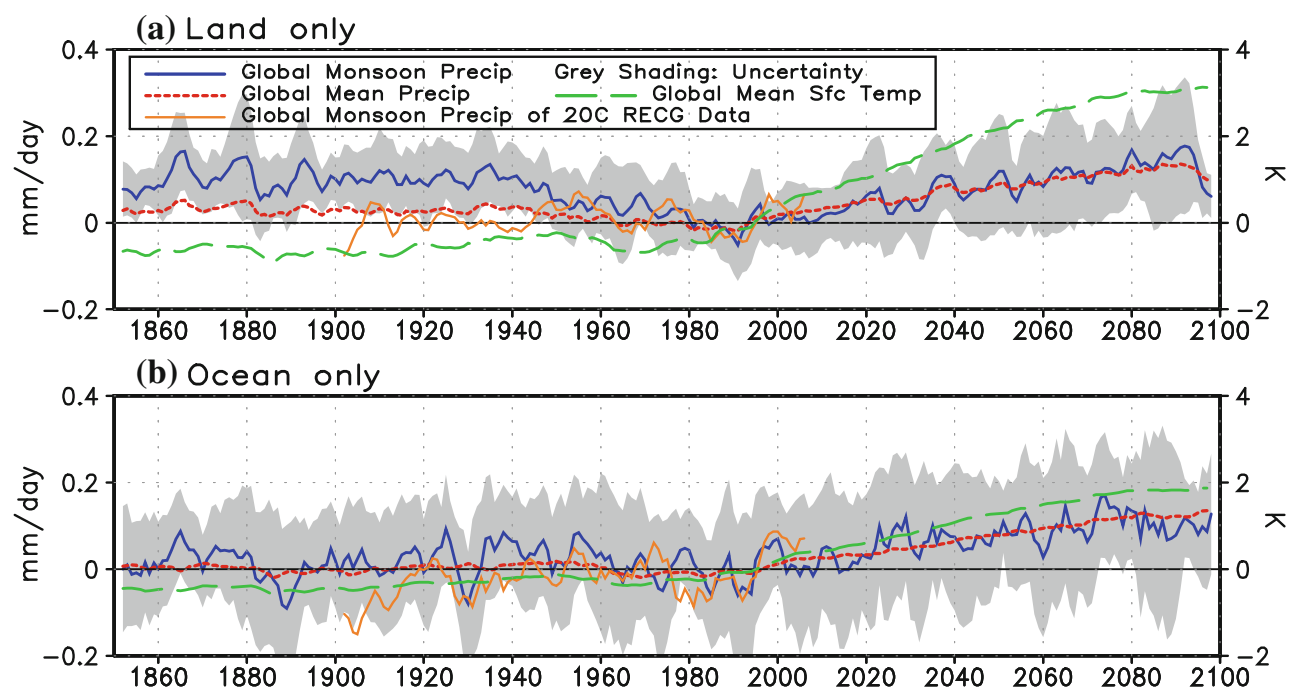

Fig. 14 Same as Fig. 11 except for a land only region and $\mathbf{b}$ ocean only region over the globe $\left(0^{\circ}-360^{\circ} \mathrm{E}, 90^{\circ} \mathrm{S}-90^{\circ} \mathrm{N}\right)$

(Fig. 11), the circulation change is dominated by interannual to interdecadal variation, particularly in 20CR (not shown). While the B4MME is able to capture changes in GM precipitation during recent 50 years, it has difficulty in capturing changes in circulation, especially the Walker cell strength (not shown). Thus, larger uncertainty is expected in the projection of circulations. Besides, large uncertainty of the 20CR data should be considered, particularly during the first half of twentieth century.

Figure 15 shows that the CMIP5 B4MME tends to predict a weakening of Walker Cell strength (an increase of westerly) that is attributable to weakening of SST gradient and pressure gradient along the equatorial Pacific due to ElNino type future warming pattern (shown in Fig. 8). The Walker Cell strength decreases by $1.6 \%$ per one degree warming that is not statistically significant considering large inter-model spread. On the other hand, DJF Hadley Cell strength increases by $4.1 \%$ per one degree warming that is comparable to inter-model spread. The results here differ from the previous studies (e.g., Tanaka et al. 2005). We also found that the CMIP3 4MME projects decreases in both the Walker and Hadley Cell strengths by 0.08 and $5.4 \%$, respectively, per one degree warming (Fig. 15). The projection of decrease of Hadley Cell strength by CMIP3 $4 \mathrm{MME}$ is more significant than that of Walker Cell strength. Further study is needed to understand why Walker circulation will not change significantly and why the projection of Hadley circulation is different between the CMIP3 and CMIP5 models.

It is noted that atmosphere is expected to be more stabilized in future that may lead to the weakening of the NH monsoon. Figure 16a and $\mathrm{b}$ shows a gradual decreasing trend of dry static stability in both upper and lower troposphere from 1980 to 2100. The negative anomaly of the dry static stability represents stabilization of atmosphere against climatological mean.
The CMIP5 models well capture the decreasing trend from 1980 to 2010 with relatively less uncertainty than the circulation, indicating the model's projection for the static stability may be more reliable than other variables.

Why will the $\mathrm{NH}$ monsoon precipitation increase in future (Fig. 11b) while the SH counterpart will not change or slightly decrease (Fig. 11c)? Figure 16c indicates the increase of the $\mathrm{NH}$ monsoon precipitation shown in Fig. $11 \mathrm{~b}$ is attributable to the increase of temperature difference between the $\mathrm{NH}$ and $\mathrm{SH}$ leading to enhancement of the Hadley circulation (Fig. 15b). This is consistent with the conclusion derived from observed results shown in Wang et al. (2012). This hemispheric differential warming pattern favors enhancement of the $\mathrm{NH}$ monsoon but weakening of the $\mathrm{SH}$ monsoon precipitation. In addition, moisture in the atmosphere is expected to be substantially increased associated with the atmospheric warming, that will also contribute to increase of the $\mathrm{NH}$ monsoon precipitation. The B4MME projects that $850-\mathrm{hPa}$ specific humidity will increase 6.6 and $5.5 \%$ per one Kelvin global mean temperature over the $\mathrm{NH}$ and $\mathrm{SH}$ monsoon region, respectively. Held and Soden (2006) also showed significant increase in lower-tropospheric water vapor in the CMIP3 models.

It is also noted that the B4MME projects significant increase in temperature difference between the Eastern and Western Hemisphere resulting in increase of east-west asymmetry (Eastern Hemisphere monsoon gets more and Western Hemisphere gets less precipitation).

\section{Summary and discussion}

Global Monsoon (GM) represents the dominant mode of the annual variation of the tropical precipitation and 
(a) Walker Cell Strength

(b) Hadley Cell Strength

The Best Four Models' MME in CMIP5
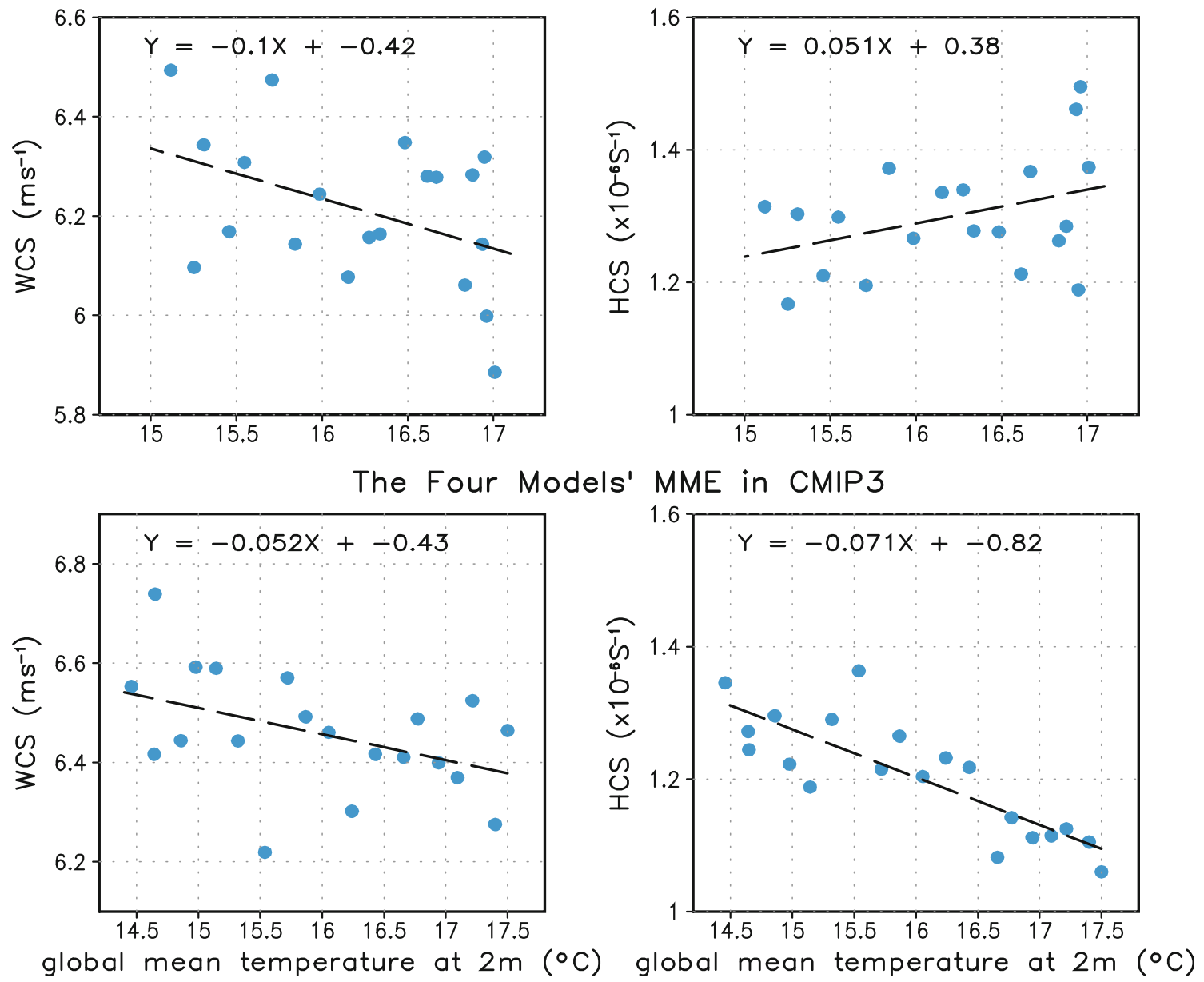

Fig. 15 Scatter diagram showing a annual mean Walker Cell Strength (WCS) and b DJF Hadley Cell Strength (HCS) as functions of global mean $2 \mathrm{~m}$-air temperature for the period of 2000-2100 in the CMIP5 B4MME (upper panels) and the CMIP3 4MME (lower

low-level winds, which defines the seasonality of Earth's climate. The annual variation of all regional monsoons can be viewed as an integrated GM system. This study investigates how much GM precipitation would increase for a given temperature increase due to a global warming and how the spatial distribution of precipitation would change using the two runs of the 20 CGCMs' simulation and projection in the CMIP5: the historical run under changing solar-volcanic forcing and anthropogenic influences from 1850 to 2005 and the RCP 4.5 run assuming that radiative forcing will stabilize at about $4.5 \mathrm{Wm}^{-2}$ after 2100 . The analysis is also applied to the two runs of 19 CGCMs in the CMIP3: twentieth-century coupled simulation (20C3M) from 1950 to 1999 and the Special Report on Emissions Scenarios (SRES) balance across all sources (A1B, $720 \mathrm{ppm}$ stabilization experiment) from 2050 to 2099.

panels). 5-year average was applied. The low-level WCS is defined by $-\mathrm{U} 850$ averaged over $10^{\circ} \mathrm{S}-10^{\circ} \mathrm{N}, 150^{\circ} \mathrm{E}-80^{\circ} \mathrm{W}$ and the $\mathrm{HCS}$ is defined by difference between 200 and $850-\mathrm{hPa}$ divergence averaged over $40^{\circ} \mathrm{E}-80^{\circ} \mathrm{W}, 5^{\circ} \mathrm{S}-10^{\circ} \mathrm{N}$

Taking into account considerable uncertainty in the GM future change projected by the state-of-the art CGCMs, optimal selection of reliable models among 20 CMIP5 CGCMs is attempted based on models' performance in simulating GM precipitation during the period of 1980-2005. A metrics used for the evaluation includes (1) the annual mean precipitation, (2) the first and second annual cycle modes of annual variation, and (3) GM precipitation intensity and domain. The selected four best models' MME (B4MME) has a higher skill for the GM metrics with less uncertainty than other subsets of MMEs over the global region of $60^{\circ} \mathrm{S}-60^{\circ} \mathrm{N}, 0^{\circ}-360^{\circ} \mathrm{E}$. It is also noted that there are some improvement from the CMIP3 to CMIP5 in simulating the GM metrics, particularly the GM precipitation intensity and domain.

By comparing the climatological GM precipitation simulated by the B4MME during the RCP4.5 run period 
(a) Static stability (T500-T200)

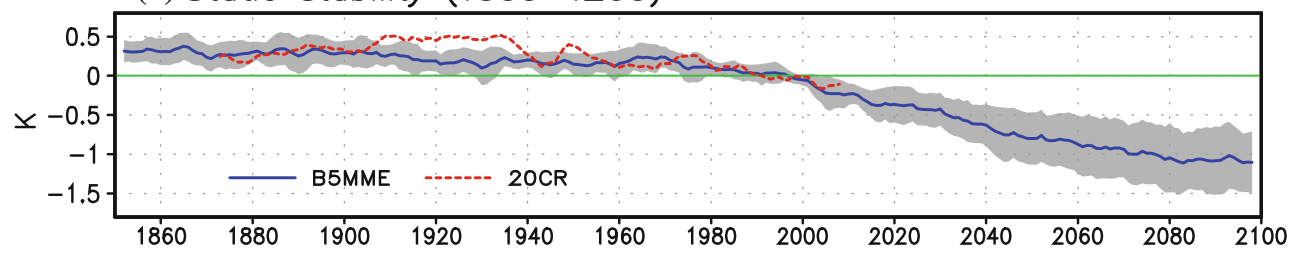

(b) Static stability (T850-T500)

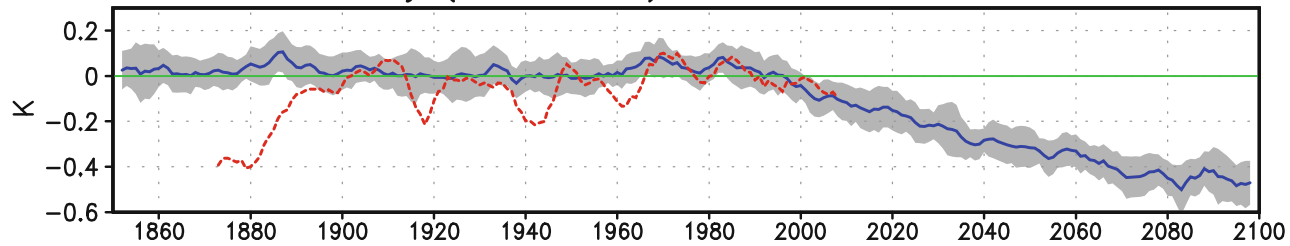

(c) $\mathrm{NH}$ and $\mathrm{SH}$ temperature difference

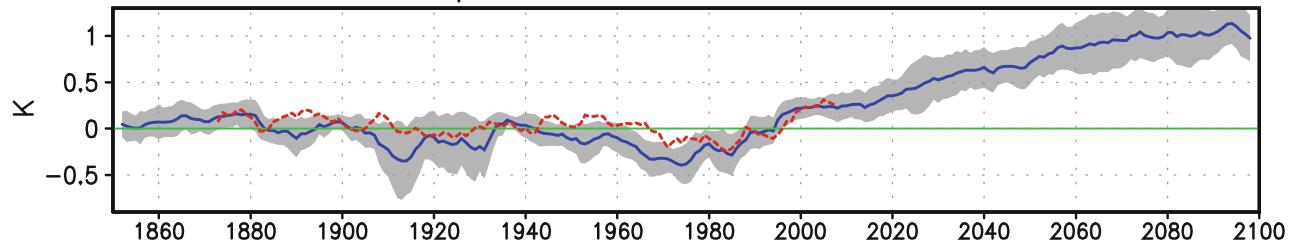

Fig. 16 Transient response of the annual mean a static stability at upper level [(T500-T200), Eq- $\left.20^{\circ} \mathrm{N}, 120^{\circ} \mathrm{W}-120^{\circ} \mathrm{E}\right], \mathbf{b}$ static stability at lower level [(T850-T500), Eq- $\left.20^{\circ} \mathrm{N}, 120^{\circ} \mathrm{W}-120^{\circ} \mathrm{E}\right]$, and $\mathbf{c}$ the $\mathrm{NH}$ and $\mathrm{SH}$ surface air temperature difference $\left[\left(\mathrm{T} 2 \mathrm{~m}, 20^{\circ} \mathrm{N}-60^{\circ} \mathrm{N}\right.\right.$, $\left.\left.120^{\circ} \mathrm{W}-120^{\circ} \mathrm{E}\right)-\left(\mathrm{T} 2 \mathrm{~m}, 40^{\circ} \mathrm{S}-\mathrm{Eq}, 120^{\circ} \mathrm{W}-120^{\circ} \mathrm{E}\right)\right]$ obtained from the

(2070-2095) with that during the historical run period (1980-2005), the projected future changes of the GM are summarized as follows.

- Monsoon domain will not change appreciably over land except Asia but will increase over oceanic monsoon regions by $6.3 \%$. The land monsoon domain over Asia tends to expand westward with $10.6 \%$ of increase in monsoon extent (Fig. 4a).

- The contribution of local summer rainfall to annual mean precipitation (monsoonality) will increase over most of the observed GM domains (including some part of the Western North Pacific-East Asia, Africa, Australia, South America monsoon) except over the South Asia and North American monsoon regions (Fig. 4b). The monsoon gets more and the desert gets less precipitation through monsoon-desert coupling. The changes are more prominent over the $\mathrm{NH}$ than the $\mathrm{SH}$.

- The annual range of the GM precipitation will amplify significantly along with increase of its annual mean over the Eastern Hemisphere monsoon region (African and Asian-Australian monsoons) while decrease over the western Hemisphere (north and South American monsoons) (Fig. 5). Overall there will be a more prominent east-west asymmetry (Eastern Hemisphere monsoon gets more precipitation and Western
CMIP5 B4MME and twentieth century reanalysis (20CR). Gray shading indicates MME's uncertainty. The anomaly was obtained from the climatology of 1980-2005. 5-year moving averaging was applied to all time series

Hemisphere monsoon get less) and north-south asymmetry (NH monsoon gets more precipitation and $\mathrm{SH}$ monsoon gets less) in global monsoon precipitation.

- During austral summer, increase in monsoon precipitation is expected over the Southern Africa and northern and southeast Australia but decrease over the South American monsoon region. During boreal summer, a significant increase of monsoon precipitation over the Asian-western North Pacific monsoon region but remarkable decrease over the North American monsoon and Venezuelan monsoon regions (Fig. 7). Thus, change of the annual range (Fig. 5b) is mainly due to local summer monsoon changes.

- It is noted that the substantial increase of the Asian monsoon precipitation in future may be attributable to enhancement and westward extension of the North Pacific Anticyclonic circulation and significant increase of atmospheric moisture over the region. On the contrary, dry region over Middle East and Western Europe will have a decrease of sea level pressure and much less increase of atmospheric moisture that together may contribute to the slight decrease of precipitation over the region (Fig. 9).

- The NH monsoon onset will be advanced and withdrawal will be delayed, indicating lengthening of 
summer monsoon period, particularly over the Asian monsoon region (Fig. 10). Results also indicate that the $\mathrm{NH}$ extratropical region with Mediterranean climate characterized by warm/hot and dry summers and mild/ cool and wet winters will expect lengthening of winter rainy period.

Analysis of transient trend of annual mean GM precipitation obtained from the B4MME and its uncertainty from 1850 to 2100 and the RECG from 1900 to 2008 reveals following characteristics of changes.

- The B4MME realistically captures the trend and interdecadal variation for the recent 50 year period, indicating the projected GM changes may be reliable to a degree, although its uncertainty is still substantial (Fig. 11a).

- The global mean of annual mean precipitation anomaly reaches about $0.12 \mathrm{~mm} \mathrm{day}^{-1}$ at year of 2100 against climatology of 1980-2005 that is about $1.9 \%$ increase per Kelvin global mean temperature. While the $\mathrm{NH}$ monsoon precipitation anomaly reaches about $0.25-0.3 \mathrm{~mm} \mathrm{day}^{-1}$ at year of 2100 (1.3\% increase per Kelvin global mean temperature), there is a slight decreasing trend in the future projection of the $\mathrm{SH}$ monsoon precipitation (Figs. 11, 12).

- The B4MME predicts the significant increase of the NH monsoon precipitation, mainly contributed by the increase of the temperature difference between the $\mathrm{NH}$ and $\mathrm{SH}$, enhancement of the Hadley circulation, and atmospheric moistening, against the stabilization of the lower as well as upper troposphere (Figs. 15, 16). There is a slight decrease of the Walker circulation but not significant against the inter-model spread.

It is noted that the CMIP5 projections for the global monsoon change well agree with the CMIP3 results. However, there are several differences.

- The CMIP5 projects a less 'wet-get-wetter and dry-getdrier' pattern than the CMIP3 does (Fig. 5).

- The CMIP5 projects a larger increase in annual mean precipitation over the entire Asian monsoon and the West African monsoon region with less uncertainty than the CMIP3 (Fig. 5).

- The CMIP3 projects much larger decrease of the North American monsoon precipitation than the CMIP5. In addition, the CMIP3 projects a slight increase of the South American monsoon precipitation but the CMIP5 predicts a significant decrease (Fig. 7b).

- The center of increased precipitation over the equatorial Pacific is located further to the east in the CMIP5 than CMIP3 (Fig. 5).

- The global mean temperature anomaly reaches at $2.2 \mathrm{~K}$ in the CMIP5 B4MME (Fig. 10) but $3.4 \mathrm{~K}$ in the
CMIP3-4MME (not shown). However, response of precipitation is larger in the CMIP5 than the CMIP3. The CMIP3 4MME projects that global mean and GM precipitation will increase 1.4 and $1 \%$, respectively, per one degree warming (Fig. 13).

- Large discrepancies exist between the CMIP 3 and CMIP 5 selected models MME in terms of change of the $\mathrm{SH}$ monsoon precipitation rates. The CMIP5 B4MME predicts $0.3 \%$ decrease of the $\mathrm{SH}$ mean monsoon precipitation per one degree warming (Fig. 12), but the CMIP3 4MME projects $0.6 \%$ increase (Fig. 13).

- The CMIP5 B4MME projects an increase of Hadley Cell strength by $4.1 \%$ per one degree warming but the CMIP3 4MME predicts a significant decrease of it by $5.4 \%$ per one degree warming. Both the CMIP5 and CMIP3 projects a decrease of Walker Cell strength but the change is insignificant in comparison with intermodel spread (Fig. 15).

It is noted that precipitation conversion from water vapor is not effective over the entire globe as well as global monsoon region. The B4MME projects 1.9 and $1.3 \%$ increase of global mean and GM precipitation, respectively, per Kelvin global mean temperature against 1980-2005 climatology. However, it is expected that 850-hPa specific humidity will increase 5.9 and $6.1 \%$ per Kelvin global mean temperature over the globe and GM region, respectively. Vecchi and Soden (2006) attributed the inefficiency to the weakening of tropical circulation in CMIP3 model. Our results using the CMIP5 models indicate that the weakening of precipitation conversion efficiency in the future projection by the CMIP5 models may be attributed to the stabilization of the atmosphere due to vertically differential warming.

Acknowledgments This work was supported by the National Research Foundation of Korea (NRF) through a Global Research Laboratory (GRL) grant (MEST 2011-0021927), APEC Climate Center, and IPRC, which is in part supported by JAMSTEC, NOAA, and NASA. We acknowledge the World Climate Research Programme's Working Group on Coupled Modeling, which is responsible for CMIP, and we thank the climate modeling groups listed in Table 1 of this paper for producing and making available their model output. For CMIP the US Department of Energy's Program for Climate Model Diagnosis and Intercomparison provides coordinating support and led development of software infrastructure in partnership with the Global Organization for Earth System Science Portals. Twentieth Century Reanalysis V2 data provided by the NOAA/OAR/ ESRL PSD, Boulder, Colorado, USA, from their Web site at http://www.esrl.noaa.gov/psd. This is the SOEST publication number 8759 and IPRC publication number 917.

Open Access This article is distributed under the terms of the Creative Commons Attribution License which permits any use, distribution, and reproduction in any medium, provided the original author(s) and the source are credited. 


\section{References}

Chou C, Tu JY, Tan PH (2007) Asymmetry of tropical precipitation change under global warming. Geophys Res Lett 34:L17708. doi:10.1029/2007GL030327

Compo GP, Whitaker JS, Sardeshmukh PD et al (2011) The twentieth century reanalysis project. Q J R Meteor Soc 137:1-28

Held IM, Soden BJ (2006) Robust responses of the hydrological cycle to global warming. J Clim 19:5686-5699

Hoskins BJ, Rodwell MJ (1995) A model of the Asian summer monsoon. Part I: the global scale. J Atmos Sci 52:1329-1340

Hsu PC, Li T, Wang B (2011) Trends in global monsoon area and precipitation over the past 30 years. Geophys Res Lett 38:L08701. doi:10.1029/2011GL046893

Hsu PC, Li T, Luo JJ, Murakami H, Kitoh A, Zhao M (2012) Increase of global monsoon area and precipitation under global warming: a robust signal? Geophys Res Lett 39:L0670. doi:10.1029/ 2012GL051037

Huffman GJ, Adler RF, Bolvin DT, Gu G (2009) Improving the global precipitation record. GPCP Version 2.1. Geophy Res Lett 36:L17808

Lee JY, Wang B, Kang IS, Shukla J et al (2010) How are seasonal prediction skills related to models' performance on mean state and annual cycle? Clim Dyn 35:267-283

Liu J, Wang B, Ding QH, Kuang XY, Soon W, Zorita E (2009) Centennial variations of the global monsoon precipitation in the last millennium: results from ECHO-G model. J Clim 22:2356-2371

Liu J, Wang B, Yim SY, Lee JY, Jhun JG, Ha KJ (2012) What drives the global summer monsoon over the past millennium? Clim Dyn 39:1063-1072

Meehl GA, Covey C, Delworth T, Latif M et al (2007a) The WCRP CMIP3 multi-model dataset: a new era in climate change research. Bull Am Meteor Soc 88:1383-1394

Meehl GA, Stocker TF, Collins WD et al (2007b) Global climate projection. In: Solomon S, Qin D, Manning $\mathrm{M}$ et al (eds) Climate change 2007: the physical science basis. Contribution of working group I to the fourth assessment report of the Intergovernmental Panel on Climate Change. Cambridge University Press, Cambridge

Neelin JD, Münnich M, Su H, Meyerson JE, Holloway CE (2006) Tropical drying trends in global warming models and observations. PNAS 103:6110-6115
Schaller N, Mahlstein I, Cermak J, Knutti R (2011) Analyzing precipitation projections: a comparison of different approaches to climate model evaluation. J Geophys Res 116:D10118

Smith TM, Arkin PA, Sapiano MRP (2010) Merged statistical analyses of historical monthly precipitation anomalies beginning 1990. J Clim 23:5755-5770

Tanaka HL, Ishizaki N, Nohara D (2005) Intercomparison of the intensities and trends of Hadley, Walker, and Monsoon circulations in the global warming projects. SOLA 1:077-080

Taylor KE, Stouffer RJ, Meehl GA (2012) An overview of CMIP5 and the experiment design. Bull Am Meteor Soc 93:485-498

Trenberth KE, Stepaniak DP (2004) The flow of energy through the earth's climate system. Quart J Meteor Soc 130:2677-2701

Trenberth KE, Stepaniak DP, Caron JM (2000) The Global monsoon as seen through the divergent atmospheric circulation. J Clim 13:3969-3993

Ueda H, Iwai A, Kuwako K, Hori ME (2006) Impact of anthropogenic forcing on the Asian summer monsoon as simulated by eight GCMs. Geophys Res Lett 33:L06703

Vecchi GA, Soden BJ (2006) Global warming and the weakening of the tropical circulation. J Clim 20:4316-4340

Wang B, Ding QH (2006) Changes in global monsoon precipitation over the past 56 years. Geophys Res Lett 33:L06711

Wang B, Ding QH (2008) Global monsoon: dominant mode of annual variation in the tropics. Dyn Atmos Oceans 44:165-183

Wang B, LinHo (2002) Rainy season of the Asian-Pacific summer monsoon. J Clim 15:386-398

Wang B, Kim HJ, Kikuchi K, Kitoh A (2011) Diagnostic metrics for evaluation of annual and diurnal cycles. Clim Dyn 37:941-955

Wang B, Liu J, Kim HJ, Webster PJ, Yim SY (2012) Recent change of the global monsoon precipitation (1979-2008). Clim Dyn 39:1123-1135

Xie P, Arkin PA (1997) Global precipitation: a 17-year monthly analysis based on gauge observations, satellite estimates, and numerical model outputs. Bull Am Meteor Soc 78:2539-2558

Yeh SW, Ham YG, Lee JY (2012) Changes in the tropical Pacific SST trend from CMIP3 to CMIP5 and its implication of ENSO. J Clim (in press). doi:10.1175/JCLI-D-12-00304.1 